\title{
Novel ACE2 protein interactions relevant to COVID-19 predicted by evolutionary rate correlations
}

\author{
Austin A Varela ${ }^{\text {Equal first author, } 1}$, Sammy Cheng ${ }^{1}$, John H Werren ${ }^{\text {Corresp. Equal first author, } 1}$ \\ ${ }^{1}$ Department of Biology, University of Rochester, Rochester, New York, United States \\ Corresponding Author: John H Werren \\ Email address: jack.werren@rochester.edu
}

Angiotensin-converting enzyme 2 (ACE2) is the cell receptor that the coronavirus SARSCoV-2 binds to and uses to enter and infect human cells. COVID-19, the pandemic disease caused by the coronavirus, involves diverse pathologies beyond those of a respiratory disease, including micro-thrombosis (micro-clotting), cytokine storms, and inflammatory responses affecting many organ systems. Longer-term chronic illness can persist for many months, often well after the pathogen is no longer detected. A better understanding of the proteins that ACE2 interacts with can reveal information relevant to these disease manifestations and possible avenues for treatment. We have undertaken an approach to predict candidate ACE2 interacting proteins which uses evolutionary inference to identify a set of mammalian proteins that "coevolve" with ACE2. The approach, called evolutionary rate correlation (ERC), detects proteins that show highly correlated evolutionary rates during mammalian evolution. Such proteins are candidates for biological interactions with the ACE2 receptor. The approach has uncovered a number of key ACE2 protein interactions of potential relevance to COVID-19 pathologies. Some proteins have previously been reported to be associated with severe COVID-19, but are not currently known to interact with ACE2, while additional predicted novel ACE2 interactors are of potential relevance to the disease. Using reciprocal rankings of protein ERCs, we have identified strongly interconnected ACE2 associated protein networks relevant to COVID-19 pathologies. ACE2 has clear connections to coagulation pathway proteins, such as Coagulation Factor $V$ and fibrinogen components FGA, FGB, and FGG, the latter possibly mediated through ACE2 connections to Clusterin (which clears misfolded extracellular proteins) and GPR141 (whose functions are relatively unknown). ACE2 also connects to proteins involved in cytokine signaling and immune response (e.g. XCR1, IFNAR2, and TLR8), and to Androgen Receptor (AR). The ERC prescreening approach has elucidated possible functions for relatively uncharacterized proteins and possible new functions for well-characterized ones. Suggestions are made for the validation of ERC-predicted ACE2 protein interactions. We propose that ACE2 has novel protein interactions that are PeerJ reviewing PDF | (2021:06:61975:1:0:NEW 23 Jul 2021) 
disrupted during SARS-CoV-2 infection, contributing to the spectrum of COVID-19 pathologies. 
2 Novel ACE2 Protein Interactions Relevant to COVID-19

3 Predicted by Evolutionary Rate Correlations

4

5

6

7

8

\author{
Austin Alves Varela ${ }^{1}$, Sammy Cheng ${ }^{1}$, John Haynes Werren ${ }^{1 @}$ \\ ${ }^{1}$ Department of Biology, University of Rochester, Rochester, NY, USA \\ (a) Contributed equally
}

Corresponding Author:

John Werren ${ }^{1}$

402 Hutchinson Hall, Rochester, NY, 14620, USA

Email address: jack.werren@rochester.edu

\title{
Abstract
}

Angiotensin-converting enzyme 2 (ACE2) is the cell receptor that the coronavirus SARS-CoV-2 binds to and uses to enter and infect human cells. COVID-19, the pandemic disease caused by the coronavirus, involves diverse pathologies beyond those of a respiratory disease, including micro-thrombosis (micro-clotting), cytokine storms, and inflammatory responses affecting many organ systems. Longer-term chronic illness can persist for many months, often well after the pathogen is no longer detected. A better understanding of the proteins that ACE2 interacts with can reveal information relevant to these disease manifestations and possible avenues for treatment. We have undertaken an approach to predict candidate ACE2 interacting proteins which uses evolutionary inference to identify a set of mammalian proteins that "coevolve" with ACE2. The approach, called evolutionary rate correlation (ERC), detects proteins that show highly correlated evolutionary rates during mammalian evolution. Such proteins are candidates for biological interactions with the ACE2 receptor. The approach has uncovered a number of key ACE2 protein interactions of potential relevance to COVID-19 pathologies. Some proteins have previously been reported to be associated with severe COVID-19, but are not currently known to interact with ACE2, while additional predicted novel ACE2 interactors are of potential relevance to the disease. Using reciprocal rankings of protein ERCs, we have identified strongly interconnected ACE2 associated protein networks relevant to COVID-19 pathologies. ACE2 has clear connections to coagulation pathway proteins, such as Coagulation Factor $\mathrm{V}$ and fibrinogen components FGA, FGB, and FGG, the latter possibly mediated through ACE2 connections to Clusterin (which clears misfolded extracellular proteins) and GPR141 (whose functions are relatively unknown). ACE2 also connects to proteins involved in cytokine signaling and immune response (e.g. XCR1, IFNAR2, and TLR8), and to Androgen Receptor (AR). The ERC prescreening approach has elucidated possible functions for relatively uncharacterized proteins and possible new functions for well-characterized ones. Suggestions are made for the validation 
40 of ERC-predicted ACE2 protein interactions. We propose that ACE2 has novel protein

41 interactions that are disrupted during SARS-CoV-2 infection, contributing to the spectrum of

42 COVID-19 pathologies.

\section{Introduction}

44 The coronavirus SARS-CoV-2 is causing severe pathologies and death among infected individuals across the planet. In addition to the symptoms expected from a respiratory disease, the infection can develop systemic manifestations (Gupta et al., 2020; Terpos et al., 2020; Siddiqi, Libby \& Ridker, 2021). As a consequence, a wide range of pathologies are associated with COVID-19, including vascular system disruption, the extensive formation of blood clots (thrombosis) resulting in microvascular injury and stroke (Magro et al., 2020; Connors \& Levy, 2020), gastrointestinal complications (Luo, Zhang \& Xu, 2020) cardiac and kidney pathologies, ocular and dermatological symptoms (Bouaziz et al., 2020), neurological manifestations (Niazkar et al., 2020; Taquet et al., 2021), male infertility (Khalili et al., 2020), and a Kawasakilike blood and heart disorder in children (Jones et al., 2020; Morand, Urbina \& Fabre, 2020). A severe and often lethal immunoreaction can occur from respiratory and other infection sites, termed a "cytokine storm" (Chen et al., 2020). Even after acute SARS-CoV-2 infection has passed, individuals can suffer a suite of complications for many months, termed "Long Haul" syndrome (López-León et al., 2021), and the causes of these syndromes are not well understood.

Angiotensin-converting enzyme 2 (ACE2) is of obvious interest because it is a primary receptor for SARS-CoV-2 entry into human cells (Lan et al., 2020). However, ACE2 also plays a role in other important processes, such as regulation of blood pressure and vasodilation by the reninangiotensin system (RAS), and protein digestion in the gut (Kuba et al., 2010). SARS-CoV-2 binding to ACE2 leads to a downregulation in ACE2 function (Verdecchia et al., 2020) which may be linked to the systemic damage by COVID-19 (Medina-Enríquez et al., 2020). It has been proposed that ACE2 receptor degradation during SARS-CoV-2 infection disrupts protection by ACE2 from inflammatory processes through the RAS and bradykinin pathways, possibly explaining patterns of COVID-19 severity with age and sex (Bastolla, 2020; Bastolla et al., 2021). As well as being a cell receptor, a circulating soluble form of the ectodomain of ACE2 (sACE2) is shed from cells and found in blood plasma, but the biological function of circulating ACE2 remains relatively unknown. Elevated levels of sACE2 have been detected in critically ill COVID-19 patients (van Lier et al., 2021) which coincides with a reduced expression of membrane-bound ACE2 (Medina-Enríquez et al., 2020), and a recent study indicates that sACE2 may assist SARS-CoV-2 entry into cells via other receptors (Yeung et al., 2021).

In general, ACE2's protein-protein interaction network is likely to contribute to COVID-19 pathologies, due to ACE2's role in systemic processes that are disrupted by the infection. Therefore, a fuller knowledge of ACE2 protein interactions is important to a better understanding of COVID-19 pathologies, including those that go beyond respiratory illness. 
77 Common methods to identify protein-protein interactions include protein co-localization and

78

79

80

81

82

83

84

85

86

87

88

89

90

91

92

93

94

95

96

97

98

99

100

101

102

103

104

105

106

107

108

109

110

111

112

113

114

115

precipitation, genetic manipulation, and proteomic profiling (Rao et al., 2014). Evolutionary approaches have also been used to evaluate protein interactions (De Juan, Pazos \& Valencia, 2013), particularly to identify functional domains within proteins based on sequence conservation in evolution. Another set of methods utilize evolutionary rate correlations (also called evolutionary rate covariance or evolutionary rate coevolution). The concept is that coevolving proteins will show correlated rates of change across evolution (Wolfe \& Clark, 2015). The approach has been used to detect physical interactions within and among proteins, as well as shared functionality not involving physical interaction, such as within metabolic pathways (Clark, Alani \& Aquadro, 2012). For example, it has been employed to identify gene networks for post-mating response (Findlay et al., 2014), ubiquitination (Böhm et al., 2016), and recombination (Godin et al., 2015), and more recently to identify DNA repair genes (Brunette et al., 2019), cadherin-associated proteins (Raza et al., 2019), mitochondrial-nuclear interactions (Yan, Ye \& Werren, 2019), and a mitochondrial associated zinc transporter (Kowalczyk et al., 2021), with subsequent experimental support. Evolutionary rate correlation (ERC) approaches are relatively inexpensive screening tools for detecting candidate protein interactions, and can also detect novel protein interactions that are not readily found in more traditional proteomic and genetic approaches (Colgren \& Nichols, 2019; Yan, Ye \& Werren, 2019). As such, "the ERC method should be a part of the toolkit of any experimental cell or developmental biologist" (Colgren \& Nichols, 2019).

We have developed an evolutionary rate correlation (ERC) method that uses well-established phylogenies based on multiple lines of evidence (e.g. Misof et al. 2014 for insects and Kumar et al. 2017 for mammals) and calculates protein evolutionary rates for terminal branches for different proteins across a set of related species (Fig. 1). The approach is predicated on the idea that proteins that have strong evolutionary rate correlations are more likely to have functional interactions that are maintained by their coevolution, a conclusion supported by its predictive power in identifying known nuclear-mitochondrial encoded protein interactions in insects (Yan, Ye \& Werren, 2019). That study also found that nuclear-encoded proteins and amino acids in contact with their mitochondrial-encoded components (e.g. oxidative phosphorylation proteins or mitochondrial ribosomal RNA) have significantly stronger ERCs than those not directly in contact. This result implicates physical interactions between proteins as one driver of evolutionary rate correlations, at least among nuclear-mitochondrial interactions. Other studies have found evolutionary rate correlations among proteins that do not make direct contact, such as in metabolic pathways (Clark, Alani \& Aquadro, 2012).

We have developed a reciprocal rank approach to identify ACE2 associated networks and propose that these strongly coevolving proteins reveal ACE2 protein interactions that could be disrupted by COVID-19, thus contributing to its diverse pathologies. Particularly noteworthy are strong connections to coagulation pathway proteins, cytokine signaling, inflammation, immunity, and viral disease response.

Peerj reviewing PDF | (2021:06:61975:1:0:NEW 23 Jul 2021) 
116 It is important to note that our approach cannot be used to study coronavirus-ACE2 coevolution.

117 The reason is that coronaviruses move between mammalian species and therefore do not have the 118 same phylogenetic history as mammalian proteins, a prerequisite for the approach. We are also 119 not asserting that coronavirus pressure is causing the evolution of ACE2 observed in the ERCs. 120 Rather, it is our proposition that the ACE2 ERCs are revealing evolved mammalian protein 121 interactions that are not caused by, but could be relevant to COVID-19 pathologies, due to 122 disruption of pathways in which ACE2 is normally involved.

123 We recognize that the predicted protein interactions detected by the ERC approach may not be

124

125

126

127

128

129

130

131

132

133

134

135

136

137

138

139

140

141

142

143

144

145

146

147

148

149

150

151

152

153 causal for COVID-19 pathologies. However, the ERC connections to coagulation pathways, cytokine signaling, and immunity are striking and suggest a possible role of these ACE2 protein interactions in COVID-19 syndromes. The ERC results may also have implications for ACE2's role in the regulation of vasodilation through the renin-angiotensin system (RAS), cardiovascular disease, and protein digestion and absorption in the gut (Kuba et al 2010). Furthermore, the ERC analysis reveals possible novel connections for coagulation pathway and cytokine-signaling proteins that may be worthy of further investigation. Therefore, validation studies of the ERC predictions described here are desirable, both for possible applications to COVID-19 disease and treatment, and for investigations of other important biological processes.

\section{Materials \& Methods}

Taxon Selection and Data Collection. Our evolutionary rate correlation (ERC) approach requires orthologous protein sequence data across a large number of taxa with well-defined phylogenetic relationships. Calculation of evolutionary rates requires a resolved phylogeny of the taxa analyzed that is scaled to evolutionary time. Our ERC calculations utilize the TimeTree (Kumar et al., 2017) to generate a time-scaled phylogenetic tree using the mammalian taxa that are represented in OrthoDB sequence data (Supplementary Fig. S1). The tree generated is in units of millions of years and is based on a compilation of many phylogenetic-dating related studies. The tree is utilized as a base topology in phylogenetic analysis and its branch lengths are used to measure time for calculating evolutionary rates from the resultant individual protein trees (Fig. 1).

Well-defined orthologous sequence data is sourced from OrthoDB (Kriventseva et al., 2019) at the "mammalia" (taxonomic id: 40674) taxonomic level. Since OrthoDB sequence data is gathered from a variety of sources and clustered algorithmically (unsupervised), primarily based on sequence similarity (Kriventseva et al., 2015), related paralogous proteins are often clustered with each other even if canonically annotated as functionally distinct proteins (Supplementary Table S1). Additionally, since the data sources for sequences can have varying levels of completeness, most ortholog groups on OrthoDB are missing sequence data for one or more taxa represented in the database. So, a majority of the data we initially selected was from single-copy ortholog groups with at least 90 of the 108 possible mammalian taxa present. In addition, some proteins with a possibly relevant function to COVID-19 pathologies (such as XCR1, and 
154 IFNAR2) or other relevant pathways in ortholog groups that did not meet the initial criteria, but

155

156

157

158

159

160

161

162

163

164

165

166

167

168

169

170

171

172

173

174

175

176

177

178

179

180

181

182

183

184

185

186

187

188

189

190

191

192 that had minimal paralogy issues, were included. Paralogous sequences were manually disambiguated based on published protein annotations and phylogenetic analysis. If a taxon in a given sequence had duplicate sequences that could not be disambiguated, the taxon was excluded in phylogenetic and ERC calculations for the specific proteins involved. In total, 1,953 orthologous protein groups are used in analyses. Additional details on the data set are provided in the Supplementary Text.

Phylogenetic Calculations and Protein Alignments. To prepare orthologous sequence data for ERC calculation, each set of protein sequences are first aligned using the MAFFT software package (Katoh \& Standley, 2013) using the following arguments: “--maxiterate 1000 --localpair --anysymbol". Since the sequences come from data sources with varying levels of quality and multiple alignment programs can be imperfect, the aligned sequences must then be trimmed. The alignments are trimmed using the trimAl software package (Capella-Gutiérrez, Silla-Martínez \& Gabaldón, 2009) using the "-automated1" argument to remove poorly aligned regions. These final prepared alignments are then used to generate maximum-likelihood phylogenies. The IQTREE software package (Minh et al., 2020) is used to estimate protein branch lengths (equivalent to average substitution counts per site). Specifically, the "LG+F+G+I" model (which utilizes an empirically derived amino acid substitution matrix) is used with the following additional parameters: “-B 1000 -st AA -seed 1234567890” and the TimeTree phylogeny is provided to constrain output tree topology to reduce possible branch length estimation errors with the "-g" option. These trees are the basis of ERC calculations. Protein branch lengths are based on the average number of changes in amino acids at each residue in the alignment. The resultant branch lengths are paired with corresponding branches in the TimeTree to quantify branch-specific rates to be used for ERC calculations (described below). ERCs calculated with the more complete phylogeny (108 species) had short branch problems in oversampled taxonomic groups (described below and in the Supplementary Text). We therefore used a reduced phylogeny consisting of 60 taxa for subsequent ERC analyses.

Calculation of ERCs. Our evolutionary rate correlation (ERC) method is designed to predict protein-protein interactions using evolutionary data (Yan, Ye \& Werren, 2019), and is based on protein evolutionary rates on terminal branches of the mammalian phylogeny (Fig. 1). We found that the more complete phylogeny (108 species) had short branch problems that inflate ERC spearman rank correlations (discussed in Supplementary Text). Most notably, there was an association between branch time and protein rate for many proteins, with oversampling in some taxonomic units (e.g. in Primates and Rodentia) leading to many ERCs being driven by relatively short branches (Supplementary Text). We attempted to control for these effects initially by using a partial correlation method, but found that it was not sufficient due to correlations between residuals and branch time (Supplementary Text). We then removed taxa that contributed short branches in our phylogeny based on either a 20MY or 30MY divergence time threshold (Supplementary Text) and recalculated branch rates for all proteins. We found that the 30MY

Peer] reviewing PDF | (2021:06:61975:1:0:NEW 23 Jul 2021) 
193 threshold short branch removal eliminated significant branch time to protein rate correlations for

194

195

196

197

198

199

200

201

202

203

204

205

206

207

208

209

210

211

212

213

214

215

216

217

218

219

220

221

222

223

224

225

226

227

228

229

the majority of proteins $(87.5 \%)$. The resultant rate data no longer has branch time to branch rate as a confounding cofactor, and the ERCs themselves are no longer biased by extremely short branches and taxonomic oversampling (Supplementary Text). The resulting data set is composed of 60 taxa and is used in our subsequent analyses of ERCs.

Using the adjusted data set, ERCs are calculated for every possible combination of protein pairs for which a tree has been generated. Every protein pair for which an ERC is calculated has each respective tree and the TimeTree topology is pruned to only include the shared taxa between the two, using the "ETE3" Python package (Huerta-Cepas, Serra \& Bork, 2016). ETE3 is also used to extract the terminal branch lengths of each pruned tree. Evolutionary rates are calculated by dividing the terminal protein-tree branch lengths (average substitutions per site) by the corresponding branch in the TimeTree (measured in millions of years). Terminal branches are used for calculations as they do not have shared evolutionary histories and are therefore independent. The resulting rates have the unit of average substitution per site per millions of years. Given the resultant rates, evolutionary rate correlations are then calculated by performing a Spearman's rank correlation test (Yan, Ye \& Werren, 2019) using the Python package "SciPy" (Virtanen et al., 2020).

Multiple Test Corrections. P-values are corrected using the Benjamini-Hochberg FDR multiple-test correction procedure implemented in the Python package "statsmodels" (Seabold \& Perktold, 2010). The FDR correction is applied to each respective protein's set of ERCs. Correlation test results are non-directional, but FDR corrections are dependent on the rank of each correlation's p-values. Since the rank of each correlation test value on respective protein lists vary, the FDR-corrected p-values of a given protein pair can differ depending on the specific ERC set. An ERC is considered significant if the FDR-corrected p-value is less than 0.05 .

ERC Set Enrichment Analysis. To summarize the common biological function of proteins that tend to have strong ERCs, gene set enrichment analysis is performed on the top 2\% of ERCs (by $\rho$ ) of each protein(s) of interest (including the protein itself), including only proteins with ERCs that are significant following an FDR correction at a significance level of 0.05. At most, a protein of interest will have 41 proteins included for enrichment analysis ( $2 \%$ of the total 1953 proteins plus itself). Protein set enrichment analyses are performed using the Enrichr service (Xie et al., 2021) via the Python bindings provided by the "GSEApy" Python package (Fang et al., 2021) given the background of the full set of 1,953 proteins. We calculate enrichment results for ACE2 and all of its top 20 ERC partners. Additional enrichment analyses were also performed on a case-by-case basis based on relevance, including the reciprocal rank networks. Enrichments are performed using selected relevant term databases: KEGG_2019_Human, GO_Biological_Process_2018,GO_Cellular_Component_2018, GO_Molecular_Function_2018, Reactome_2016,WikiPathways_2019_Human,

Peerj reviewing PDF | (2021:06:61975:1:0:NEW 23 Jul 2021) 
230 Tissue_Protein_Expr_from_Human_Proteome_Map,

232 Enrichment results for terms that are significant at FDR-adjusted $\mathrm{p}<0.05$ for all analyses are 233 placed into a single table, organized by the enrichment term database (Supplementary File S3).

234 The outputs from different databases can contain redundant terms to each other, so only the most 235 significant of the redundant terms are reported for any enrichment analysis in the main text.

236 Reciprocal Rank Network (RRN) Generation. To evaluate and visualize the strongest ERCs 237 centered around proteins of interest, "reciprocal rank networks" (RRNs) are produced.

238 Reciprocal ranks refer to the fact that a significant ERC between two proteins can have different 239 ranks in the two respective protein ERC lists because some proteins have more and higher ERCs 240 than others. To focus on networks of proteins with strong reciprocal rank correlations, we have 241 constructed networks based on proteins with reciprocal ranks of 20 or less (RR20), which is the 242 top $1 \%$ in each protein's highest ERCs based on $\rho$ values. Specifically, we have developed an 243 ACE2 centric reciprocal rank network by the following steps (1) for ACE2, select its top 1\% (20) 244 proteins, (2) for each of those proteins, select additional proteins in their ERC list with reciprocal rank 20 or less, and then (3) Given the core set of proteins generated in the previous two steps, connect proteins which have a unidirectional rank of 20 or less.

247 The resultant network represents the strongest ERCs centered around a protein of interest (in this 248 case ACE2), along with the immediate neighborhood of the strongest ERCs surrounding the 249 protein of interest. The ACE2 Core Reciprocal Rank (CRR) was initiated with the four proteins 250 to which ACE2 has RR20 ERCs (CLU, TMEM63C, FAM3D, and L1CAM), with GPR141 251 added due to its RR1 strong connection to CLU and unidirectional connection to ACE2. ACE2 252 also has highly significant ERCs to proteins that do not rank it in their top one percent. 253 Therefore, a similar approach has been used to generate an ACE2 reciprocal network initiated 254 with the top 10 proteins to which ACE2 has highly significant ERCs, but are not reciprocally 255 RR20 ranked, with a subsequent one cycle RR20 built upon these. This ACE2 Unidirectional 256 Reciprocal Rank Network (URR) contains strong network connections to ACE2 through its high 257 unidirectional ERCs. Steps 2-3 were omitted as the network becomes extremely large following just the first step, and our focus is on examining close connections to ACE2 based on ERC analysis.

ERCs Within and Between Protein Complexes. To compare whether calculated ERCs are 262 stronger between known interactions versus non-interactions, the protein complex database, CORUM (Giurgiu et al., 2019), was used to retrieve known complexes. The "Core Complex" dataset was downloaded and filtered for human complexes to eliminate redundancy, resulting in 233 protein complexes from this CORUM data set which have two or more components present in our 1,953 protein ERC set, representing 258 pairwise ERC comparisons. As these protein complexes have redundancy (i.e. some complexes contain overlapping protein pairs), the set was 
267

268

269

270

271

272

273

274

275

276

277

278

279

280

281

282

283

284

285

286

287

288

289

290

291

292

293

294

295

296

297

298

299

300

301

302

303

304

further restricted to complexes containing unique protein components - resulting in 139 effective unique complexes considered. To test whether ERCs within complexes are higher than between complexes, all pairwise ERCs within complexes were compared to the median $\rho$ value for each pair to proteins present in non-redundant CORUM set that are not in complex with either of these proteins. A Wilcoxon matched signed-rank test was performed using the "wilcox.test" function in base R (version 3.6.1; with parameters "paired" and "exact" set to "TRUE") on the incomplex $\rho$ values and the median out-of-complex $\rho$ values, to test if the in-complex $\rho$ values were significantly greater than the median out-of-complex $\rho$ values. In addition, as there were many complexes with a majority of subcomponents not present in our 1,953 datasets, the likelihood of individual pairs directly interacting within the complex decreases with the increasing number of proteins in a complex. Therefore, an additional Wilcoxon matched signedrank test was performed on members of protein complexes composed of five or fewer proteins.

Testing for Taxonomic Effects. We use three methods to test for taxonomic effects on the calculated ERCs, (1) multiple linear regression, (2) analysis of covariance (ANCOVA), and (3) non-parametric independent contrasts (Garland, Harvey \& Ives, 1992). For the regression and ANCOVA approaches, rate data was grouped by mammalian taxonomic orders accessed via ETE3 (Huerta-Cepas, Serra \& Bork, 2016) and treated as an independent variable. The independent contrasts test uses the mammalian topology previously created with TimeTree (Kumar et al., 2017) to generate independent contrasts within the phylogeny. Statistical tests for each method are performed using base R (version 3.6.1). See the Supplementary Text for details.

\section{Testing Whether Branch Rates Increase When Extending Branch Time Within Clades. To} test whether increasing branch length results in increasing protein evolutionary rate, we selected separate phylogenetic groups (clades) from the full phylogeny (Supplementary Fig. S1) that contain short branch lengths. Protein evolutionary rate was calculated for each protein on the short branch, and then sequentially recalculated after removing adjacent taxa to extend the branch internally (Supplementary Fig. S5). In this way, the protein evolutionary rate was examined as branches are extended internally in independent clades within the tree. Comparing original branches to the $20 \mathrm{MY}$ correction resulted in 12 clades for which time scales change between 20MY and 30MY corrections, and 16 clades for which time scales change between $0 \mathrm{MY}$ and 30MY. Tests on each branch's rate against the respective adjusted rate were performed using two-tailed Wilcoxon Matched Signed Rank Tests (Base R v3.6.1), first for proteins of interest (e.g. ACE2) and then for the full protein set. Results are described in the Supplementary Text.

\section{Results}

A. Basic Approach. The basic methods are outlined here to provide context for the results which follow. To identify candidate protein interactions using evolutionary rate correlation, we utilized the consensus TimeTree phylogenetic reconstruction for mammalian species (Kumar et al., 2017). A total of 1,953 proteins (including ACE2) were aligned and evolutionary rates for each 
305

306

307

308

309

310

311

312

313

314

315

316

317

318

319

320

321

322

323

324

325

326

327

328

329

330

331

332

333

334

335

336

337

338

339

340

341

342

protein were then calculated for terminal branches of the tree (Fig. 1). This was determined by dividing the protein-specific branch length on each terminal branch by terminal branch time from the consensus tree (Yan, Ye \& Werren, 2019). Maximum likelihood branch lengths were estimated in IQ-TREE (Minh et al., 2020) using an empirical amino acid substitution matrix (see methods for details). To investigate evolutionary rate correlations (ERCs) among proteins, Spearman rank correlations were calculated for every protein pair using terminal branch rates (Fig. 1). Due to the large number of comparisons, a Benjamini-Hochberg false discovery rate (FDR) correction was calculated for each protein's ERC set (significance threshold $\alpha=0.05$ ). We subsequently found that many proteins show a positive correlation between terminal branch time and evolutionary rate, and observed that short branches in relatively oversampled taxa significantly contributed to this correlation (Supplementary Text). We, therefore, removed species that accounted for short branches, which eliminated the protein evolutionary rate to branch time correlation (see Methods and Supplementary Text for details). ERCs were then recalculated, and our ERC analyses are based on this set of 60 taxa.

In addition, we tested whether the observed lower rates of protein evolution for short terminal branches in the phylogeny are due to rates actually increasing over evolutionary time, versus a taxonomic effect. This was accomplished by examining changes in protein rates in independent clades as terminal branches were effectively extended by selective removal of flanking taxa. The analysis shows that evolutionary rates for many proteins increase as branch length is increased (described in more detail in Supplementary Text, Supplementary Fig. S4). A possible explanation for the pattern is that protein coevolution is mostly episodic, and short branches in a phylogeny are less likely to capture such events. In additional analyses, we tested for but did not find significant confounding effects of taxonomy on the ERC results (Supplementary Text).

Our analyses are focused on candidate protein interactions involving ACE2 using evidence of highly significant ERCs. For this purpose, we first examine proteins in ACE2's highest $2 \%$ of ERCs (top 40 proteins), all of which are highly significant after FDR correction (Table 1). Some of these ACE2 ERC proteins have been previously implicated in severe COVID-19 or SARSCoV-2 gene expression effects on infected cells. However, while they have not been previously identified as having protein interactions with ACE2, this is predicted by our ERC analysis.

X-C Motif Chemokine Receptor 1 (XCR1) provides an illustrative example. XCR1 is a cytokine signaling receptor and ACE2's 2nd highest ranked ERC, with a highly significant evolutionary rate correlation. XCR1 is in a small genomic region that is implicated in severe COVID-19 by genome-wide association studies (Severe Covid-19 GWAS Group, 2020; Fricke-Galindo \& Falfán-Valencia, 2021). Another example is Interferon alpha/beta receptor 2 (IFNAR2) which, in a genome-wide association study (GWAS) and multi-omic analysis by Pairo-Castineira et al. (2021), was implicated in severe COVID-19. We therefore added it to our analysis, and surprisingly found it to be highly ranked (5th) among ACE2 ERCs. Clusterin (CLU) is the 3rd strongest ERC of ACE2 and the ACE2-CLU pair show high reciprocal ranks to each other (3rd 
343 in ACE2's set, 8th in CLU's set). CLU prevents the aggregation of misfolded proteins in the 344 blood and delivers them to cells for degradation in lysosomes (Sánchez-Martín \& Komatsu, 345 2020). CLU connects to key proteins in the coagulation pathway based on its reciprocal rank 346 network (Section C, Fig. 2). CLU has been implicated in coronavirus infections, as one of only 347 two proteins showing significant expression changes in cells infected by three different 348 coronaviruses tested, including SARS-CoV-2 (Singh et al., 2021). The examples above lend 349 credence to the proposition that the ERC approach is detecting ACE2 protein interactions that 350 have implications to COVID-19.

351 Differences in ERC rank between protein pairs for the same correlation can occur because some

352

353

354

355

356

357

358

359

360

361

362

363

364

365

366

367

368

369

370

371

372

373

374

375

376

377

378

379

380 proteins have higher and more extensive ERC connections than others. As a result, while two proteins can have a significant ERC with each other, each one's rank may differ in their respective ERC lists, as illustrated for ACE2 and GEN1 (Table 1). GEN1 (Flap endonuclease GEN homolog 1) is ACE2's top-ranked ERC, and is a DNA nuclease whose primary functions are resolution of DNA Holliday junctions and DNA damage checkpoint signaling (Chan \& West, 2015). This protein shows high ERCs and is ranked highly in the ERC sets for many other proteins, suggesting central connectivity. As described further in Section C2, GEN1 shows unexpected enrichments for immune functions, perhaps related to its role in DNA damage checkpoint signaling.

Because our focus is on identifying strong candidate interactions involving ACE2 and its predicted partners, we utilize the rank information to identify proteins with high reciprocal ranks. Specifically, we focus on the strongest reciprocal ranks (RR) defined by ranks of less than or equal to 20 (RR20), which is the highest one percent of each protein's ERCs, and use these to develop reciprocal rank networks (Section C). Although speculative, we posit that protein pairs with high reciprocal ranks are likely to be strongly coevolving (i.e. both partners evolving reciprocally due to selective pressures acting on interacting domains between them). In contrast, protein pairs with a significant evolutionary rate correlation only one ranks highly (e.g. within the top two percent) in the ERC set of the other, are more likely to be due to "unidirectional" evolution. The rationale is that proteins with many significant ERC partners are under selective pressures primarily from their top evolutionary partners, whereas other interactors evolve primarily in response to the forces shaped by their stronger partner(s). We emphasize that this interpretation is speculative, and requires further exploration to determine what factors shape reciprocal ERC ranks between proteins.

The view that ERCs are detecting protein interactions relevant to COVID-19 is further supported by the analysis of ACE2 reciprocal rank ERC networks (Section C). Noteworthy in this regard are additional proteins in the coagulation pathway, such as Coagulation Factor V (F5), Fibrinogen Alpha Chain (FGA), Fibrinogen Beta Chain (FGB), and Fibrinogen Gamma Chain (FGG). Thrombosis (blood clotting) is a major pathology of COVID-19 (Gupta et al., 2020). Connections of ACE2 with the proteins above could relate to severe blood clotting problems in 
381

382

383

384

385

386

387

388

389

390

391

392

393

394

395

396

397

398

399

400

401

402

403

404

405

406

407

408

409

410

411

412

413

414

415

416

417

COVID-19 infections. ACE2 networks also show strong enrichments of cytokine signaling, viral (and pathogen) infections, and inflammatory response terms (Supplementary File S3), which are clearly relevant to COVID-19 pathologies such as cytokine storms and systemic inflammation.

In yet other cases, we have found proteins with significant ACE2 ERCs or ACE2 network connections, but for which there is little functional information, such as GPR141. We can use their ERCs to suggest possible functions for future investigation. Finally, ERCs for proteins of known function (such as F5 and GEN1) indicate likely additional roles, suggesting these proteins have unrecognized "moonlighting" functions (Jeffery, 1999).

Below, we first describe proteins of interest to which ACE2 has significant ERCs, summarize aspects of their known biological functions, and examine significantly enriched functional categories for these ERCs. We then build and evaluate two different networks for ACE2 interacting proteins (Section C), one of which reveals connections to coagulation pathways and the other to cytokine-mediated signaling, viral response, and immunity. Finally, we discuss the potential implications of these predicted ACE2 interactions to COVID-19 pathologies and propose some specific hypotheses that emerge from this analysis.

\section{B. Top ERC Interactions Link ACE2 to COVID Pathologies. To investigate protein} associations of ACE2, we first determined the protein enrichment categories for its top 2\% ERC proteins (based on Spearman rank correlation coefficients, $\boldsymbol{\rho}$ ) using the gene set enrichment package Enrichr (Xie et al., 2021) (Table 2). The top two KEGG_2019_Human enrichments are for complement and coagulation cascade related (FDR $=2.0 \mathrm{E}-03)$ and cytokine-cytokine receptor interaction related (FDR $=2.0 \mathrm{E}-03$ ) terms. This finding is consistent with two hallmarks of COVID-19 pathology, abnormal systemic blood-clotting (thrombosis) and cytokine storms (Coperchini et al., 2020; Fei et al., 2020). Additionally, several terms related to viral/bacterialspecific infection are significantly enriched, such as Tuberculosis (FDR $=1.4 \mathrm{E}-02), \mathrm{HPV}$ infection (FDR $=1.4 \mathrm{E}-02)$, measles $(\mathrm{FDR}=2.4 \mathrm{E}-02)$ and Hepatitis $\mathrm{C}(\mathrm{FDR}=3.1 \mathrm{E}-02)$. Gene Ontology Biological Process also shows enrichment for tumor necrosis factor (TNF) pathways, including the signaling pathway (FDR $=3.9 \mathrm{E}-03)$ and cellular responses $(\mathrm{FDR}=1.6 \mathrm{E}-02)$. Additional terms are shown in Table 2.

The ACE2 ERC analysis indicates that ACE2 is "coevolving" with proteins involved in the complement and coagulation pathways, cytokine signaling, TNF, and pathogen response pathways. Here, we summarize results and background information on some of the key proteins among ACE2's ERCs (more extended summaries of each protein are in the Supplementary Text).

Among ACE2's strongest ERCs are proteins involved in immunity. For example, XCR1 (X-C Motif Chemokine Receptor 1) is ACE2's 2nd top-ranked ERC ( $\rho=0.67$, FDR $=6.2 \mathrm{E}-05$ ). It is a chemokine XCL1 receptor involved in immune response to infection and inflammation (Lei \& Takahama, 2012). Strikingly, the Severe Covid-19 GWAS Group (2020) detected a small 
418 genomic region containing six genes that significantly associate with severe COVID-19, one of 419 which is XCR1. Our finding that XCR1 is ACE2's 2nd highest ERC interactor lends independent 420 support for a relationship between COVID-19 and XCR1. Furthermore, it suggests that an 421 interaction between ACE2 and XCR1 could be involved in COVID-19 pathologies. To our 422 knowledge, there are no other reports of interactions between these two proteins.

423

424

425

426

427

428

429

430

431

432

433

434

435

436

437

438

439

440

441

442

443

444

445

446

447

448

449

450

451

452

453

454

Another striking connection of ACE2 ERC to immunity is through IFNAR2 (Interferon alpha/beta receptor 2), which has a highly significant ACE2 ERC correlation $(\rho=0.62$, FDR $=$ 6.1E-04). IFNAR2 forms part of an important receptor complex with IFNAR1 (Thomas et al., 2011) involved in interferon signaling through the JAK/STAT pathway to modulate immune responses. IFNAR2 has been implicated in severe COVID-19, based on mendelian randomization, genome-wide associations, and gene expression changes (Liu et al., 2021; PairoCastineira et al., 2021). Our data provide independent support for a role, possibly mediated through ACE2 interactions. Interferon pathways are important in antiviral defense, but also can contribute to cytokine storms and COVID-19 pathologies (McKechnie \& Blish, 2020). Other immune-related proteins with high ERC connections to ACE2 include TLR8 (Toll-like Receptor 8), FAM3D (FAM3 metabolism regulating signaling molecule D), and PLA2G7 (phospholipase A2 group VII).

Coagulation pathway proteins figure prominently in ACE2 ERC-predicted protein interactions (Table 3, Fig. 2). This is reflected both in significant enrichment for coagulation cascade proteins in the top 2\% strongest ACE2 ERCs (Table 2) and the strong reciprocal rank network for ACE2 (Section C, Fig. 3). The finding has obvious potential implications to a hallmark pathology of COVID-19, systemic coagulopathy (Wright et al., 2020; Medcalf, Keragala \& Myles, 2020). A list of coagulation and blood-related proteins associated with ACE2 is presented in Table 3. Among ACE2's top 2\% ERCs associated with coagulation pathway are Coagulation Factor V (F5), Protein C inhibitor (SERPINA5 aka PCI), and Thrombin Receptor 2 (F2RL2) (Table 1).

Also relevant to coagulopathy are Clusterin (CLU) and the orphan G protein-coupled receptor 141 (GPR141). The chaperone protein CLU has a soluble form that circulates in the blood and is part of the "cleaning squad" that clears misfolded extracellular proteins for delivery to lysosomes and degradation (Itakura et al., 2020; Sánchez-Martín \& Komatsu, 2020). It is the 3rd highest ACE2 ERC ( $\rho=0.63, F D R=1.5 \mathrm{E}-04)$, and these two proteins show strong reciprocal ranks (3, 8), likely supporting biological interactions. Relevant to this point is that both ACE2 and CLU have soluble forms that circulate in the blood (Itakura et al., 2020). Of direct relevance to COVID-19 and possible ACE2-CLU protein interactions, Singh et al. (2021) found in cells infected with different coronaviruses (SARS-CoV-2, SARS-CoV, and MERS-CoV), only two genes were found to be differentially expressed in all three, with CLU being one.

CLU's top 2\% strongest ERCs show highly significant enrichment for terms relating to coagulation cascades and clot formation (Supplementary File S3, e.g. "Complement and

Peerj reviewing PDF | (2021:06:61975:1:0:NEW 23 Jul 2021) 
455 coagulation cascades", $\mathrm{FDR}=6.3 \mathrm{E}-12$ ), as well as significant terms that are relevant to 456 immunity, such as "Immune system" (FDR = 4.8E-03) and "activated immune cell type" (FDR = 457 3.4E-05). Among its top ERC proteins relevant to coagulation process are Coagulation Factor $\mathrm{V}$ $458(\mathrm{~F} 5, \rho=0.67, \mathrm{FDR}=9.1 \mathrm{E}-06$, rank 3), Fibrinogen Gamma chain $(\mathrm{FGG}, \rho=0.59$, FDR $=1.7 \mathrm{E}-$ 459 04, rank 18), Coagulation Factor XIII B chain (F13B, $\rho=0.63$, FDR = 2.8E-05, rank 19), and 460 Fibrinogen Alpha chain (FGA, $\rho=0.57$, FDR = 2.9E-04, rank 27) (Fig. 3, Supplementary File 461 S1). Notably, fibrinogen is a major binding "client" of Clusterin in stressed plasma (Wyatt \& 462 Wilson, 2010). Little is known about GPR141; however, the ERC analysis suggests an important 463 role in blood coagulation. Among GPR141's top ERC proteins relevant to coagulation process 464 are Kininogen $1(\mathrm{KNG} 1, \rho=0.60, \mathrm{FDR}=9.3 \mathrm{E}-04$, rank 5), Plasminogen Activator (PLAT, $\rho=$ 4650.58, FDR $=6.5 \mathrm{E}-04$, rank 6), Thrombin (Coagulation Factor II or F2, $\rho=0.58$, FDR $=6.5 \mathrm{E}-04$, 466 rank 7), Fibrinogen Beta chain (FGB, $\rho=0.57$, FDR $=6.5 \mathrm{E}-04$, RR 11, 11), Complement C1s $467(\mathrm{C} 1 \mathrm{~S}, \rho=0.54, \mathrm{FDR}=1.6 \mathrm{E}-03$, rank 22), F2R-like thrombin (also called trypsin receptor 3; 468 F2RL3, $\rho=0.52$, FDR $=2.6 \mathrm{E}-03$, rank 37), and Coagulation Factor V $(\mathrm{F} 5, \rho=0.52, \mathrm{FDR}=$ 469 1.7E-03, rank 39) (Fig. 2, Supplementary File S1).

470 GPR141 has a highly significant ERC to CLU, with these two proteins being each other's first 471 ranking ERCs $(\rho=0.68, \mathrm{FDR}=9.1 \mathrm{E}-06, \mathrm{RR} 1,1)$. The pattern suggests a strong biological 472 interaction, although none is described in the literature. The result supports investigating 473 functional interactions between CLU and GPR141, based upon their high ERC and reciprocal ranks. Our network analysis (Section $\mathrm{C}$ ) further supports extensive interconnections among ACE2, Clusterin, GPR141, and coagulation pathway proteins, implicating the protein interaction pathway as a possibly significant contributor to disruption of coagulation in COVID-19 disease. Coagulation cascade proteins found in the ACE2's top 2\% ERCs, ACE2 reciprocal rank network, and Clusterin-GPR141 associated proteins are highlighted in Figure 2.

479

480

481

482

483

484

485

486

487

488

489

490

491

492

Androgen Receptor (AR, $\rho=0.57, \mathrm{FDR}=8.8 \mathrm{E}-04$, rank 13) is the receptor for the male hormone androgen. It plays a major role in reproductive system development, somatic differentiation, and behavior (Matsumoto et al., 2008). Androgen-AR signaling induces ACE2 (Wu et al., 2020), while knockdowns of AR result in downregulation of ACE2 (Samuel et al., 2020). AR agonists also reduce SARS-CoV-2 spike protein-mediated cellular entry (Deng et al., 2021). Additionally, AR is associated with COVID-19 comorbidities (Dolan et al., 2020), and recently implicated in the severity of COVID-19 in women with polycystic ovarian syndrome, a disorder associated with high androgen levels and androgen sensitivity (Gotluru et al., 2021). Our ERC finding indicating ACE2 and AR coevolution suggests regulatory feedback between these two proteins, which could be relevant to COVID-19 severity and other sex differential pathologies, such as cardiovascular disease (Viveiros et al., 2021).

Other notable significant ACE2 ERCs (Table 1) include Metabolism regulating signaling molecule D (FAM3D), Transmembrane-protein 63C (TMEM63C); Collagen Type IV Alpha 4 (COL4A4), L1 cell adhesion molecule (L1CAM), and ITPRIP-like 2 (ITPRIPL2). More detailed 
493 information on these and other proteins mentioned in this section is provided in Section C and 494 the Supplementary Text.

495 C. ERC Reciprocal Rank Networks Implicate Coagulation Pathways and Immunity. As 496 mentioned previously, two proteins with a significant evolutionary rate correlation (ERC) may 497 often "rank" each other differently in their respective top ERC connections. This occurs because 498 some proteins have more extensive ERC connections than others. High reciprocal ERC ranks 499 between protein pairs may be more indicative that they are under strong coevolutionary pressure 500 in their sequence and function. We have thus found it useful to evaluate these reciprocal rank 501 connections as a network. The rationale is that such proteins are likely to be reciprocally

502 evolving ("coevolving"). To build reciprocal rank networks, we use protein pairs that 503 reciprocally share ranks less than or equal to 20 (RR20), which are the top one percent for each 504 protein's respective ERC set.

505 A core ACE2 reciprocal rank network was generated by building reciprocal rank connections 506 (RR20) outward of ACE2, to provide a backbone set of RR20 protein connections. The backbone 507 was expanded on by adding the RR20 connections of the non-ACE2 backbone proteins.

508 Unidirectional ERCs ( $\leq$ rank 20) were then added between proteins within the RR set to produce 509 an ACE2 Core Reciprocal Rank (CRR) Network (Fig. 3). The network is designed to capture 510 features of ACE2's protein interactions as revealed by the strong reciprocal evolutionary 511 correlations among proteins.

512 ACE2 also has highly significant ERCs to proteins that do not rank ACE2 within their top 1\% of 513 ERCs, due to those proteins having more protein interactions with higher ERCs. A second 514 network was therefore generated using ACE2's top ten unidirectional ERCs, followed by 515 calculating the RR20 associations for those proteins. This second network is referred to as the 516 ACE2 Unidirectional Reciprocal Rank (URR) Network (Fig. 4).

517 These are presented below. In general, the reciprocal ranks analysis lends credence to our 518 proposition that ERCs reveal real biological interactions, as well as providing predictions for 519 novel protein interactions possibly of importance to COVID-19 pathologies and protein520 interaction networks.

521 C1. The ACE2 Core Reciprocal Rank (CRR) Network. The CRR network (Fig. 3) is designed 522 to capture essential features of ACE2's protein interactions as revealed by the strong reciprocal 523 correlations among proteins.

524 The most striking aspects of the ACE2 CRR Network are extensive connections to the 525 coagulation pathway and blood-associated proteins (Fig. 3, Table 3). This could be relevant to 526 COVID-19 due to extensive clotting pathologies and stroke associated with COVID-19 527 (Bonaventura et al., 2021), as well as microvascular clotting and the apparent shut-down of 528 fibrinolysis (Wright et al., 2020). Extensive blood coagulation of COVID-19 patients can even 
529 lead to clogging of dialysis equipment (Rabb, 2020). This hallmark pathology of COVID-19 530 indicates a disruption in coagulation and fibrinolysis pathways, and our findings of extensive 531 network connections between ACE2 and coagulation-fibrinolysis pathway proteins could be 532 relevant. The predicted novel protein interactions detected here may also have implications more 533 generally to circulatory system homeostasis, including regulation of blood pressure and 534 coagulation.

535 ACE2 connects to coagulation pathway proteins through F5, CLU, FAM3D, and GPR141 (Fig. 536 2, Fig. 3). CLU-GPR141 form a high RR ERC (ranks 1,1), strongly suggesting coevolution of 537 these proteins and physical/functional interactions. Both CLU and GPR141 then connect to the 538 fibrinogen proteins FGB and FGG. FGA, FGB, and FGG are the three protein components that 539 make up fibrinogen, which during the clotting process are converted into fibrin monomers, 540 which subsequently cross-link to form the fibrin clot (Mosesson, 2005). All three proteins form

541

542

543

544

545

546

547

548

549

550

551

552

553

554

555

556

557 558

559

560

561

562

563

564

565

566 an RR20 triad, indicating protein coevolution. FGG is a hub for RR ERCs to several other proteins (e.g. CD34, CPB2, C14or129, and ZBTB43). ZBTB43 is noteworthy, as it is associated with the blood diseases Diamond-Blackfan Anemia 4 and Hemochromatosis Type 2 (Stelzer et al., 2016). The former disrupts red blood cell formation in the bone marrow and the latter causes iron accumulation in the body. In terms of tissue distribution, ZBTB43 is enhanced in bone marrow (Uhlén et al., 2015). Cellularly, it is found mainly in nucleoplasm and nucleoli, suggesting regulatory functions, as might be expected for a transcription factor-like zinc finger domain protein. Most noteworthy, Mamoor (2020) has shown that ZBTB43 is differentially expressed in human microvascular endothelial cells and human cell cultures infected with coronaviruses (e.g MERS-CoV and human coronavirus 229E). So, this is yet another member of the ACE2 protein Network which is implicated in coronavirus infection. In turn, ZBTB43 has a RR connection with SERPINF2, which enhances clotting by inhibiting plasmin, an enzyme that degrades fibrin, the main component of clots. Mutations in SERPINF2 can cause severe bleeding disorders and upregulation of SERPINF2 is implicated in COVID-19 patient thrombosis (Jain et al., 2021; Lazzaroni et al., 2021). In turn, CPB2 (Carboxypeptidase B2) is a thrombin-activated inhibitor of fibrinolysis, and therefore enhances clotting stability (Leenaerts et al., 2018), and also plays a role in activating the complement cascade (Morser et al., 2018; Leung \& Morser, 2018).

FAM3D is a cytokine for neutrophils and monocytes in peripheral blood which may interact with ACE2 based on their reciprocal ranking. ACE2 is its 2nd ranking ERC. Although ACE2 does not have a significant ERC to F13B (also known as Coagulation Factor XIII B Chain), it is FAM3D's top-ranking ERC. F13B functions to stabilize clotting through cross-linking of fibrin (Stelzer et al., 2016). Thus, the predicted interaction of FAM3D and F13B may be relevant to the coagulation pathway.

Blood pressure and vasoconstriction regulation also show functional enrichment in the CRR network. Naturally, ACE2 is a crucial component of the Renin-Angiotensin System (RAS), 
567

568

569

570

571

572

573

574

575

576

577

578

579

580

581

582

583

584

585

586

587

588

589

590

591

592

593

594

595

596

597

598

599

600

601

602

603

which converts angiotensin II to angiotensin (1-7). This, in turn, binds to the MAS1 receptor, promoting vasodilation and reduced blood pressure. As seen in Figure 2, MAS1 is part of the ACE2 CRR network. Although not significantly correlated with ACE2 directly, it has significant RR connection to TSHZ3 ( $\rho=0.52$, FDR $=7.8 \mathrm{E}-03$, ranks 11,4$)$ and is FAM3D's 19th ranking ERC $(\rho=0.49$, FDR $=1.5 E-02)$. Biologically MAS1 and ACE2 are key elements promoting vasodilation in the renin-angiotensin system (RAS) (Burrell et al., 2004). Thus, the ERC RR network detects biologically significant connections of ACE2 to RAS signaling via the MAS1 receptor of angiotensin-(1-7). Samavati \& Uhal (2020) posit that the loss of ACE2 due to SARSCoV-2 infection reduces MAS1 signaling and increases AT1 \& AT2 signaling via higher levels of angiotensin 2, promoting vasoconstriction, fibrosis, coagulation, vascular and cardio injury, and ROS production. Similar arguments are made by Sriram \& Insel (2020). ACE2 and MAS1 do not have a signature of protein coevolution, even though they interact indirectly biologically through the short seven amino acid signaling peptide Ang (1-7). In contrast, MAS1 has a significant RR with TSHZ3 (mentioned above). A biological connection between these proteins is not obvious, although the high ERC reciprocal ranks suggest possible interactions worth further investigation. Additionally, TMEM63C is one of four proteins that form a reciprocal rank ERC association with ACE2 (Figure 2). It functions in osmolarity regulation and like ACE2, interacts with angiotensin II, possibly reducing damage to kidney podocytes (Eisenreich et al., 2020).

FBXL3 has a RR20 connection to FGB and ranks GPR141 in its top 2\%. This protein is a component of circadian rhythm regulation (Busino et al., 2007). Many aspects of the cardiovascular system have circadian cycling such as heart rate, blood pressure, and fibrinolysis (Reilly, Westgate \& FitzGerald, 2007). Endogenous oscillators in the heart, endothelial cells, and smooth muscles may play significant roles in these cycles (Reilly, Westgate \& FitzGerald, 2007), and the CRR network suggests that interactions between FBXL3 and FGB could play a role in circadian aspects of fibrinolysis.

CD34 (Hematopoietic Progenitor Cell Antigen CD34) is believed to be an adhesion protein for hematopoietic stem cells in bone marrow and for endothelial cells (Fina et al., 1990). Our ERC analysis indicates connections to coagulation pathway proteins and lipoproteins. In addition to its RR association with FGG ( $\rho=0.60$, FDR $=2.2 \mathrm{E}-04$, ranks 18,9$)$, CD34 also forms significant reciprocal rank correlations with coagulation factor F2 $(\rho=0.69$, FDR $=7.9 \mathrm{E}-06$, ranks 1,6$)$, lipoprotein APOE $(\rho=0.64$, FDR $=6.0 \mathrm{E}-05)$, lipid droplet-associated protein PLIN1 $(\rho=0.64$, FDR $=1.1 \mathrm{E}-04$, ranks 8,7), and inflammation associated pentraxin protein PTX3 ( $\rho=0.65$, FDR $=6.8 \mathrm{E}-05$, ranks 3,11) (Supplementary File S1). As expected from these protein associations, CD34's top enriched term is to complement and coagulation cascade (FDR $=1.4 \mathrm{E}-08)$. There is also enrichment for HUVEC cells (FDR = 3.1E-05) and Blood Plasma (FDR = 1.7E-04) (Supplementary File S3). 
604 Additional proteins of interest are discussed further in the supplementary materials, including 605 TSHZ3 (a key regulator of airflow and respiratory rhythm control) and L1CAM (involved in 606 nervous system development and vascular endothelial cell differentiation from stem cells).

607 Consistent with the descriptions above, the CRR network shows enrichment (full enrichment 608 table in Supplementary File S3) for negative regulation of blood coagulation (FDR $=4.3 \mathrm{E}-08)$, 609 platelet alpha granule-related terms $(\mathrm{FDR}=1.7 \mathrm{E}-05)$, plasma cell $(\mathrm{FDR}=8.3 \mathrm{E}-4)$ and blood clot 610 (FDR $=4.5 \mathrm{E}-02)$. These enrichments indicate that the network involves protein interactions 611 related to blood clotting pathways. There are also several significantly enriched terms which are 612 driven in part by ACE2, such as regulation of systemic arterial blood pressure by renin613 angiotensin $(\mathrm{FDR}=1.6 \mathrm{E}-03)$, metabolism of angiotensinogen to angiotensin ( $\mathrm{FDR}=6.9 \mathrm{E}-03)$, 614 regulation of blood vessel diameter $(\mathrm{FDR}=1.5 \mathrm{E}-02)$, and renin-angiotensin system $(\mathrm{FDR}=$ 615 1.8E-02).

616 C2. The ACE2 Unidirectional Reciprocal Rank (URR) Network. ACE2 also has highly 617 significant ERCs with interacting proteins that are unidirectional, meaning that ACE2 ranks 618 these proteins in its top 2\%, but the partner protein does not rank ACE2 within its top 2\% due to 619 higher ERC correlations with other partners (Table 1). Some of ACE2's highest-ranking proteins 620 fall into this category, including GEN1 (rank 1), XCR1 (2), IFNAR2 (5) KIF3B (6), and 621 ITPRIPL2 (7), FAM227A (8), TLR8 (9), COL4A4 (10), F5 (12), and AR (13). To focus on 622 strong protein connections in this set, we took the top ten proteins with unidirectional ERCs for 623 ACE2 and then added their reciprocal rank 20 (RR20) partners. The resulting ACE2

624 Unidirectional Reciprocal Rank (URR) Network contains 69 proteins (Fig. 4).

625 Notable in the network are many proteins involved in immunity and cytokine signaling, such as 626 IFNAR2 (Interferon alpha/beta receptor 2), XCR1 (X-C Motif Chemokine Receptor 1), and 627 ICOS (Inducible T Cell Costimulator). There are also Toll-Like Receptors TLR8 and TLR9, 628 which stimulate innate immune activity (Forsbach et al., 2011), and Tumor Necrosis Factor 629 related proteins such as TNSFS18, TNTSF15, TNFRSF9, and TNRRSF1A.

630 Enrichment analysis of the URR network generates 72 significant terms (Supplementary File 631 S3). The network is highly enriched for cytokine-cytokine receptor interaction (FDR $=6.5 \mathrm{E}-06$ ), 632 I-kappaB kinase/NF-kappaB signaling $(\mathrm{FDR}=1.6 \mathrm{E}-06)$, necroptosis $(\mathrm{FDR}=3.3 \mathrm{E}-03)$, viral 633 infections, such as Human Papillomavirus (FDR $=5.7 \mathrm{E}-04$ ) and Herpes virus (FDR $=3.5 \mathrm{E}-03$ ), 634 JAK-STAT and PI3K-AKT signaling pathways, Toll-like receptor signaling, and immune system 635 Homo sapiens (FDR $=3.7 \mathrm{E}-03)$.

$636 \mathrm{XCR} 1$ is the 2nd highest ACE2 ERC. It is the receptor for chemokine XCL1, which is produced 637 in response to infection and inflammation, and during development of regulatory T cells (Lei \& 638 Takahama, 2012). Furthermore, XCR1 maps to a region implicated in severe COVID-19 by a 639 genome-wide association study (Severe Covid-19 GWAS Group, 2020). As seen in Figure 4, 640 XCR1 forms a RR subnetwork with six other proteins (ICOS, CCR5, WDR66, TNSFS15, 
641 PRSS38, and FAM227A), three of which are known to be involved in immunity. ICOS 642 (Inducible T Cell Costimulator) is reciprocally evolving with XCR1 based on their ERC 643 interaction. It is an inducible $\mathrm{T}$ Cell stimulator that is essential for $\mathrm{T}$ helper cell responses 644 (Hutloff et al., 1999; Tafuri et al., 2001). In addition, ICOS signaling is impaired in COVID-19 645 patients requiring hospitalization (Hanson et al., 2020). The high ERC between ACE2 and XCR1 646 and high reciprocal ranks of XCR1 to ICOS suggests that the disruption of an ACE2-XCR1 647 interaction could have a contributory role in COVID-19. C-C Motif Chemokine Receptor 5 648 (CCR5) forms a significant RR ERC with XCR1 as well. Several studies have implicated CCR5 649 variation and expression to be associated with COVID-19 severity (Gómez et al., 2020; Hubacek 650 et al., 2021; Kasela et al., 2021), while others have not (Bernas et al., 2021). TNFSF15 is a third 651

652 immune response protein in the XCR1 RR subnetwork that shows elevated expression in patients

653

654

655

656

657

658

659

660

661

662

663

664

665

666

667

668

669

670

671

672

673

674

675

676

677

678

679 with severe COVID-19 (Jain et al., 2021). We recognize that the involvement of these immunerelated proteins in COVID-19 does not require an effect mediated through ACE2. Instead, their protein evolutionary correlations suggest that ACE2 may play a contributory role to COVID-19, possibly through XCR1-related pathways, as suggested by the network analysis.

IFNAR2 is another protein that is highly correlated with ACE2 $(\rho=0.62$, FDR $=6.1 \mathrm{E}-04)$ and is also implicated in severe COVID-19 by GWAS and expression data (Liu et al., 2021; PairoCastineira et al., 2021). It has RR20 ERCs with ten other proteins and is embedded in a complex web of interactions with members of the ACE2 network. Here we draw attention to a few key features. Notably, IFNAR2 and IFNAR1 are RR partners, as expected given that they combine to form the IFN-alpha/beta receptor, which is the receptor for both alpha and beta interferons. IFNAR2 forms a high RR relationship with TNFRSF1A ( $\rho=0.84$, FDR $=4.8 \mathrm{E}-12,1,1$ reciprocal ranks). This protein is the receptor for $\mathrm{TNF} \alpha$ and the pathway affects apoptosis and inflammation regulation. Jin et al. (2015) found that ACE2 deletion increases inflammation through TNFRSF1A signaling, lending further support to a functional association between ACE2 and this protein.

GEN1 is the highest-ranking ACE2 ERC protein $(\rho=0.67, \mathrm{FDR}=4.2 \mathrm{E}-05)$, and it functions as a resolvase of Holliday junctions and a DNA damage checkpoint signaling (Chan \& West, 2015). Frankly, we are perplexed by the functional significance of ACE2-GEN1 correlated evolution. As observed in the ACE2 network, GEN1 is a highly interconnected protein, with 14 RR20 connections in the network. This result suggests that GEN1 may have additional functions beyond DNA replication. Indeed, although its second-highest RR is to CC2D1B (2,1), a protein involved in mitosis, its highest RR is to Interferon Lambda Receptor 1 (IFNLR1), with an impressive Spearman correlation of $\rho=0.89$ (FDR $=6.2 \mathrm{E}-17)$. As IFNLR1 binds cytokine ligands and stimulates antiviral response, this suggests some feedback mechanism between GEN1 and the immune system, possibly related to its functional role in DNA damage checkpoint signaling. Indeed, its top 2\% ERCs show enrichment for multiple viral infection terms (Supplementary File S3). Therefore, it appears that GEN1 has a "hidden life" that ERC analysis suggests warrants exploration. 
680 The Collagen Type IV A4 subnetwork (Fig. 4, Fig. 5) lends further credence to the view that 681 ERCs can detect proteins with likely binding partners. COL4A4 is a component of the Collagen 682 Type IV protein complexes in basement membranes in the extracellular matrix of various tissues, 683 including the kidney glomerulus and vascular endothelial cells, and lung alveoli (Myllyharju \& 684 Kivirikko, 2001). COL4A4, COL4A3, and COL4A5 complex with each other in the basement 685 membranes of kidney glomeruli - mutations in these COL4A proteins are known to cause 686 different kidney disorders (Torra et al., 2004; Wiradjaja, DiTommaso \& Smyth, 2010). 687 Consistent with their expected binding, COL4A4 and COL4A3 are each other's reciprocal best 688 partners (ranks 1,1$)$ and highly correlated with each other $(\rho=0.88$, FDR $=4.4 \mathrm{E}-16)$. Both show 689 highly significant ERCs to COL4A6 (rank 6,5 for COL4A4 $\rho=0.83$, FDR $=2.1 \mathrm{E}-12$; rank 22,30 690 for COL4A3 $\rho=0.78, \mathrm{FDR}=1.6 \mathrm{E}-10)$. Thus, evolutionary rate correlations show highly 691 significant ERCs among Collagen Type IV proteins known to physically interact. A future 692 direction is to use ERCs to more precisely define predicted coevolving protein segments, which 693 could be used to inform docking simulations and experimental studies.

694 COL4A5 also has significant ERCs to COL4A3 $(\rho=0.71$, FDR $=2.2 \mathrm{E}-08)$ and COL4A4 $(\rho=$ 6950.71$, FDR $=1.7 \mathrm{E}-08)$, but these do not qualify as RR20 due to the large number of high ERCs 696 for COL4A5. Interestingly, COL4A5-MUC15 are top-ranking partners (ranks 1,1) with a very 697 high ERC ( $\rho=0.89, \mathrm{FDR}=3.2 \mathrm{E}-16)$. MUC15 is a cell surface protein that is believed to 698 promote cell-extracellular matrix adhesion and it is implicated in affecting influenza infection 699 (Chen et al., 2019), which may increase its relevance in the context of COVID-19 infection. 700 ERCs may help to inform candidate domains within each protein that are involved in their 701 expected binding affinity.

702 Coagulation Factor V (F5) is known for its role in the coagulation cascade. However, F5 is a 703 highly ERC-connected protein, with 43 proteins ranking it in their respective top 5 highest ERCs. 704 This connectedness is also reflected in the RR20 network shown below (Fig. 6). F5 has 16 RR20 705 connections out of the maximum 20 possible. Although F5 is a vital protein in the coagulation 706 cascade, its top $16 \mathrm{RR}$ connections indicate immune functions, including Interferon $\lambda$ receptor 1 707 (IFNLR1; RR 4,10) and Oncostatin M Receptor (OSMR; RR 1,4). This is reflected in the 708

709

710

711

712

713

$714(\mathrm{FDR}=1.9 \mathrm{E}-03)$ and cytokine receptor activity $(\mathrm{FDR}=2.1 \mathrm{E}-02)$ for C5orf34. In conclusion, F5

715 appears to have a "secret life" of strong protein interactions reflecting moonlighting functions 716 with extensive signaling or modulation roles beyond coagulation regulation. 
717 D. ERCs and Protein Interactions. We postulate that ERCs detect proteins that are coevolving

718 due to functional interactions. Furthermore, we propose that physical binding is an important

719 mechanism contributing to significant ERCs between proteins. This is consistent with anecdotal

720 observations from this study of high reciprocal rank ERCs among the fibrinogen components

721 FGA, FGB, \& FGG, the Collagen Type IVA proteins COL4A4, COL4A3, and COL4A6

722 proteins, and Interferon alpha/beta proteins IFNAR2 and IFNAR1.

723 To further investigate the role of binding affinity, we examined the mammalian protein complex 724 database CORUM (Giurgiu et al., 2019) to determine whether significantly higher Spearman

725 rank correlations ( $\rho$ values) are found among proteins within known protein complexes. A set of

726139 protein complexes (excluding those with overlapping proteins) were identified which

727 contain at least two members from our ERC data set, for a total of 258 pairwise comparisons. We

728 compared the $\rho$ values of within complex proteins to the median values for proteins outside the

729 complex and found that Spearman rank correlations of within complex proteins were

730 significantly higher than its between complex values according to Wilcoxon matched signs rank

731 tests (WMRST) under a significance level of $\alpha=0.05(\mathrm{p}=5.2 \mathrm{E}-04)$, with a median increase of

$7326.3 \%$ (Supplementary File S11). Many of the complexes contain large numbers of proteins,

733 reducing the probability of direct physical contact between individual members. We therefore

734 also analyzed only proteins from complexes with 5 or fewer members (96 pairs). In this case, the

735 median $\rho$ value increase is $15.8 \%$ (WMSRT $p=6.2 \mathrm{E}-03$ ). The results support the view that

736 proteins within known complexes show higher ERCs than between complexes, and further

737 implicate physical contact as a contributor to ERCs. However, other studies have found ERCs

738 between proteins that do not bind to each other, but are involved in shared function, such as

739 metabolic pathways (Clark, Alani \& Aquadro, 2012). Thus, future research is needed to better

740 understand the different biological drivers of ERCs between proteins.

\section{Discussion}

742 An overwhelmingly strong pattern is an association between ACE2, its partners, and the proteins

743 involved with coagulation, cytokine signaling, and immunity. For coagulation, this is

744 exemplified by the enrichment for terms related to coagulation pathways in the CRR network,

745 and the presence of the three proteins that form fibrinogen (FGA, FGB, FGG) which constitutes

746 the clotting molecule fibrin. Abnormal clotting and coagulation such as "hypercoagulability" has

747 been observed as a major symptom of COVID-19 infection (Fei et al., 2020). Additionally,

748 disseminated intravascular coagulation (DIC) due to COVID-19 has been found more frequently

749 in fatal cases of COVID-19 than non-fatal cases (Seitz \& Schramm, 2020). Levi et al. (2020)

750 have noted that low-grade DIC often seen in COVID-19 is associated with a sudden decrease in

751 plasma fibrinogen before death. This makes the connection with the various fibrinogen

752 subcomponents even more striking. Our network data suggest that ACE2's connection to

753 fibrinogen is mediated through Clusterin and GPR141 (Fig. 3). The chaperone protein

754 Clusterin's role in removing misfolded proteins in the blood and its common association with

755 fibrinogen in blood plasma (Wyatt \& Wilson, 2010) lend credence to these ERC findings. What 
756

757

758

759

760

761

762

763

764

765

766

767

768

769

770

771

772

773

774

775

776

777

778

779

780

781

782

783

784

785

786

787

788

789

790

791

792

793

remains unclear is the nature of potential functional interactions between ACE2 and Clusterin, but the ERC results suggest that this warrants further attention. The discovery of a strong ERC association of Clusterin and GPR141 is a novel finding, as functional information on GPR141 is largely lacking. ERC analysis indicates that these proteins functionally interact, likely involving coagulation processes.

Another mechanism for ACE2's influence on the coagulation effects of COVID-19, based on ERCs, is through F5. F5 canonically is activated by the same enzyme (Thrombin) that converts fibrinogen into fibrin for clotting (Omarova et al., 2013). Omarova et al. (2013) further report that inhibition of $\mathrm{F} 5$ can enhance an anticoagulant ability of an alternate fibrinogen that utilizes a different isoform of FGG, fibrinogen $\gamma^{\prime}$. Thus, we hypothesize that abnormal coagulation activity may (in part) be driven by disruptions in ACE2-F5 protein interactions, which could reduce anticoagulant feedback mechanisms. F5 is also found to have many significant ERCs outside of the coagulation pathway, connecting to various immunity-related pathways (Fig. 4, Supplementary File S1). The ERC results for GPR141 and F5 reveal how ERC analysis may be useful in providing testable hypotheses for functions of understudied proteins, and to investigate additional functional roles on well-studied proteins.

A second major finding is ACE2 protein-protein interactions that connect to cytokine signaling and immunity. "Cytokine storms", an overreaction of the immune system which can lead to inflammation and organ failure, is a second major hallmark of severe COVID-19, and its management is a major target of medical treatment research (Luo et al., 2020; Mangalmurti \& Hunter, 2020). Chemokines are a class of cytokines that act as immune cell attractants (Coperchini et al., 2020), and an increase in chemokine production may be characteristic of COVID-19 infection (Coperchini et al., 2020). XCR1 is a receptor of XCL1 chemokines, mostly expressed in dendritic cells, and plays a role in cytotoxic immune responses (Lei \& Takahama, 2012). The XCR1 protein, strikingly, is the second-highest ERC to ACE2 and has already been implicated in severe COVID-19 infection (Severe Covid-19 GWAS Group, 2020). While the specific mechanism by which XCR1 might play a role in severe COVID-19 is not yet known, ERC results indicate its role may be mediated by ACE2 with XCR1's ERCs also possibly indicating a broader functional role in coagulation. Excessive Inflammatory response, particularly as a consequence of cytokine storms, is a clear pathology or COVID-19.

Type 1 interferons are among the first types of cytokines produced after viral infection (GarcíaSastre \& Biron, 2006; Sallard et al., 2020). A component of the type 1 interferon receptor, IFNAR2, is among the strongest ACE2 ERCs, possibly linking ACE2 to the type 1 interferon immunity response. Notably, IFNAR2 has been implicated in severe COVID-19 infection (PairoCastineira et al., 2021). Since type 1 interferons have shown some initial efficacy in treating COVID-19 infection (Sallard et al., 2020), it is possible that the SARS-CoV-2 virus interaction with both receptor and soluble ACE2 interferes with type 1 interferon response, as low levels of type 1 interferons have been found in COVID-19 patients (Salman et al., 2021). Another 
794 connection of ACE2 with immunity may be mediated by the toll-like receptor TLR8 (a strong

795

796

797

798

799

800

801

802

803

804

805

806

807

808

809

810

811

812

813

814

815

816

817

818

819

820

821

822

823

824

825

826

827

828

829

830

831

832

833

ACE2 ERC), among TLRs believed to regulate platelet circulation in response to inflammation (Beaulieu \& Freedman, 2010) providing possible avenues for interaction with soluble ACE2 in blood. Genetic variants in TLRs (including TLR8) may affect COVID-19 susceptibility (Lee, Lee \& Kong, 2020). Thus, there are many potential avenues for ACE2 protein interactions contributing to immune dysregulation in COVID-19 disease, which may warrant further investigation given the strong ERC associations of ACE2 with proteins relevant to immunity, although the functional bases of such interactions are unknown. Other ACE2 network ERCs of interest are relevant to kidney disease, cardiovascular disease, male fertility, Alzheimer's disease, and DNA damage checkpoint signaling. These are discussed further in the Supplementary Text.

Overall, the underlying concept behind the evolutionary rate correlation approach (also called evolutionary rate covariance or evolutionary rate coevolution) is that coevolving proteins will show correlated rates of change across evolution and that this reflects functional interactions (Clark, Alani \& Aquadro, 2012; Wolfe \& Clark, 2015). Clark and colleagues have developed a web interface (https://csb.pitt.edu/erc_analysis/) to screen for ERC interactions for Drosophila, yeast, and mammals. Their mammalian data set is based on 33 mammalian species (Priedigkeit, Wolfe \& Clark, 2015; Wolfe \& Clark, 2015). We have compared their output for ACE2 to our analyses and found only one overlapping protein (XCR1) between their significant ERCs $(\mathrm{p}<$ 0.05 ) and our top $2 \%$ ACE2 ERCs. There are many methodological differences between our approaches, including the number and specific mammalian taxa used, the method for calculating protein rates, and the phylogeny used for calculating branch lengths. In addition, their dataset includes 17,487 proteins, whereas our analysis is currently restricted to 1,953 proteins for which we were confident about 1:1 orthology and therefore for which there are minimal paralogy complications. Furthermore, we are uncertain how their database dealt with potential short branch artifacts on ERC calculations. In our case, we found that short branches in the phylogeny resulted in significant correlations between branch time and protein rate, thus both inflating estimated ERCs and introducing branch time as a confounding factor which can lead to spurious correlations, and we removed these by branch trimming.

In another study, Braun et al. (2020) applied a "phylogenetic profiling" approach to identify ACE2 interacting proteins relevant to possible drug targets for COVID-19. Phylogenetic profiling generally screens multiple genomes for presence-absence correlations of protein combinations, as a method to detect candidate protein interactions (Pellegrini et al., 1999). However, Braun et al. (2020) use a modification of the method that also incorporates a BLASTbased distance metric from human ACE2 across taxa ranging from humans to fungi. When we focus on proteins common between our set and their mammalian data set (1,875 proteins), there are three shared proteins among the top 1\% for both sets, Androgen Receptor (AR) and Angiomotin (AMOT), and nucleotide excision repair protein homolog MMS19, with no additional proteins in the respective top $2 \%$ sets. We suggest that our direct measures of protein evolutionary rates, which utilize aligned sequences and phylogenetic analysis, may be a more

Peer) reviewing PDF | (2021:06:61975:1:0:NEW 23 Jul 2021) 
834 sensitive approach for finding evolutionary interactions among proteins in mammals. Obviously, 835 future validation studies are needed to reveal which approaches are most effective at detecting 836 candidate protein interactions, or whether each has its own merits for the detection of different 837 interactions.

838

839 Experimental validations of novel ACE2 protein associations predicted by our ERC approach are

840

841

842

843

844

845

846

847

848

849

850

851

852

853

854

855

856

857

858

859

860

861

862

863

864

865

866

867

868

869

870

871

872

clearly needed. A necessary first step is to establish whether ACE2 has binding affinities in vitro and in vivo with proteins showing high evolutionary correlation to it, in particular CLU, XCR1, GEN1, and IFNAR2. Similar binding affinity is predicted between CLU and GPR141 based on their high reciprocal rank ERCs. CLU-FGG and GPR141-FGB provide connections to fibrinogen based on their evolutionary correlations, suggesting binding affinities. Applicable methods could include protein complex immunoprecipitation, tagged protein analysis, and yeast-two-hybrid analysis (Rao et al., 2014).

We have begun preliminary analyses using short (10mer) amino acid sequences to identify predicted sites of interaction among protein partners. These data may be able to inform docking simulations for protein pairs using software that allows for the incorporation of a priori predicted interfaces (Van Zundert et al., 2016; Pagadala, Syed \& Tuszynski, 2017). For example, these 10 mer analyses can be used to determine likely regions of binding affinity between ACE2 and Clusterin, for experimental validation through mutational analysis. Similarly, coagulation factor $\mathrm{V}$ shows high ERCs for non-canonical proteins, which can be investigated to determine whether F5 has novel functions outside of the coagulation pathway.

\section{Conclusions}

In this paper, we take an exploratory approach to $\mathrm{ACE} 2$ protein interactions using evolutionary rate correlations. Our key findings are that the ERC analysis predicts ACE2 to have previously unidentified protein partners, and to be part of interaction networks relevant to COVID-19 pathologies. Most notably, ACE2 forms strong ERC networks relevant to coagulation and immunity. A potential mechanism is that reduced abundance of membrane-bound ACE2 disrupts signaling networks. Additionally, the presence of the soluble ACE2 ectodomain may explain the systemic pathologies of COVID-19 infection as its circulation in the blood can affect pathways throughout the body. We recognize that the new ACE2 protein connections predicted by ERCs may not be causal in severe COVID-19 pathologies. However, our novel findings that the ACE2 ERC network connects to coagulation and immunity pathways is noteworthy, with clear potential implications to some of the unusual features of COVID-19. In addition, results may have relevance to other functions of ACE2, such as circulatory homeostasis and digestion. The ERC analysis predicts additional protein connections that can be relevant to biological processes and disease. For instance, ERCs predict novel interactions for cytokine and immunity related proteins, such as for XCR1, IFNLR1, IFNAR2, and TLR8. Future investigations of the ERC networks of these and related proteins could be worthwhile. ERCs also suggest strong but previously undescribed connections for proteins, such as CLU, GPR141, F5, and GEN1. 
873 Validation studies are necessary to determine to what extent strong ERCs predict biological

874 interactions among proteins, such as the ones detected here.

875 Further computational analyses of ERCs are needed to better understand their relationship to

876 protein function and evolution. For instance, machine learning and simulation approaches can be

877 used to determine which aspects of protein structure, amino acid properties, and rates of protein

878 evolution, improve ERC predictive power. We are currently expanding the mammalian protein

879 set for such analyses. Finally, if evidence mounts that ERCs can be informative in predicting

880 protein interactions, the approach can be applied more broadly as an additional tool for detecting

881 protein interaction networks involved in many biological processes and disease.

\section{Acknowledgements}

883 We thank Zhichao Yan for guidance with the mammalian protein database and discussions on

884 ERC methods and independent contrasts. Also thanked are J. Fay, J. Fry, J. Jaenike, A. Kingsley,

885 A. Larracuente, E. Sia, S. Ghaemmaghami for discussions and helpful feedback, and M.

886 Tsuchiya for support and helpful discussions. Special thanks also go to Nathaniel and Helen

887 Wisch for their support.

888

889

890

891

892

893

894

895

896

897

898

899

900

901

902

903

904

905

906

907

908

909

910

911

912

913

914

\section{References}

Aase K, Ernkvist M, Ebarasi L, Jakobsson L, Majumdar A, Yi C, Birot O, Ming Y, Kvanta A, Edholm D, Aspenström P, Kissil J, Claesson-Welsh L, Shimono A, Holmgren L. 2007. Angiomotin regulates endothelial cell migration during embryonic angiogenesis. Genes and Development 21:2055-2068. DOI: 10.1101/gad.432007.

Bastolla U. 2020. Mathematical model of SARS-Cov-2 propagation versus ACE2 fits COVID-19 lethality across age and sex and predicts that of SARS, supporting possible therapy. arXiv Preprint.

Bastolla U, Chambers P, Abia D, García-Bermejo M-L, Fresno M. 2021. Is Covid-19 severity associated with ACE2 degradation? arXiv Preprint.

Beaulieu LM, Freedman JE. 2010. The role of inflammation in regulating platelet production and function: Toll-like receptors in platelets and megakaryocytes. Thrombosis Research 125:205-209. DOI:

10.1016/j.thromres.2009.11.004.

Bernas SN, Baldauf H, Wendler S, Heidenreich F, Lange V, Hofmann JA, Sauter J, Schmidt AH, Schetelig J. 2021. CCR5 32 mutations do not determine COVID-19 disease course. International Journal of Infectious Diseases 105:653-655. DOI: 10.1016/j.ijid.2021.02.108.

Böhm S, Szakal B, Herken BW, Sullivan MR, Mihalevic MJ, Kabbinavar FF, Branzei D, Clark NL, Bernstein KA. 2016. The budding yeast ubiquitin protease Ubp7 is a novel component involved in s phase progression. Journal of Biological Chemistry 291:4442-4452. DOI: 10.1074/jbc.M115.671057.

Bonaventura A, Vecchié A, Dagna L, Martinod K, Dixon DL, Van Tassell BW, Dentali F, Montecucco F, Massberg S, Levi M, Abbate A. 2021. Endothelial dysfunction and immunothrombosis as key pathogenic mechanisms in COVID-19. Nature Reviews Immunology 21:319-329. DOI: 10.1038/s41577-021-00536-9.

Bouaziz JD, Duong TA, Jachiet M, Velter C, Lestang P, Cassius C, Arsouze A, Domergue Than Trong E, Bagot M, Begon E, Sulimovic L, Rybojad M. 2020. Vascular skin symptoms in COVID-19: a French observational study. Journal of the European Academy of Dermatology and Venereology 34:e451-e452. DOI: $10.1111 /$ jdv.16544.

Bratt A, Birot O, Sinha I, Veitonmäki N, Aase K, Ernkvist M, Holmgren L. 2005. Angiomotin regulates endothelial cell-cell junctions and cell motility. Journal of Biological Chemistry 280:34859-34869. DOI: 
915

916

917

918

919

920

921

922

923

924

925

926

927

928

929

930

931

932

933

934

935

936

937

938

939

940

941

942

943

944

945

946

947

948

949

950

951

952

953

954

955

956

957

958

959

960

961

962

963

10.1074/jbc.M503915200.

Braun M, Sharon E, Unterman I, Miller M, Shtern AM, Benenson S, Vainstein A, Tabach Y. 2020. ACE2 Coevolutionary Pattern Suggests Targets for Pharmaceutical Intervention in the COVID-19 Pandemic. iScience 23:101384. DOI: 10.1016/j.isci.2020.101384.

Brunette GJ, Jamalruddin MA, Baldock RA, Clark NL, Bernstein KA. 2019. Evolution-based screening enables genome-wide prioritization and discovery of DNA repair genes. Proceedings of the National Academy of Sciences of the United States of America 116:19593-19599. DOI: 10.1073/pnas.1906559116.

Burrell LM, Johnston CI, Tikellis C, Cooper ME. 2004. ACE2, a new regulator of the renin-angiotensin system. Trends in Endocrinology and Metabolism 15:166-169. DOI: 10.1016/j.tem.2004.03.001.

Busino L, Bassermann F, Maiolica A, Lee C, Nolan PM, Godinho SIH, Draetta GF, Pagano M. 2007. SCFFbxl3 controls the oscillation of the circadian clock by directing the degradation of cryptochrome proteins. Science 316:900-904. DOI: 10.1126/science.1141194.

Capella-Gutiérrez S, Silla-Martínez JM, Gabaldón T. 2009. trimAl: A tool for automated alignment trimming in large-scale phylogenetic analyses. Bioinformatics 25:1972-1973. DOI: 10.1093/bioinformatics/btp348.

Chan YW, West S. 2015. GEN1 promotes Holliday junction resolution by a coordinated nick and counter-nick mechanism. Nucleic Acids Research 43:10882-10892. DOI: 10.1093/nar/gkv1207.

Chen ZG, Wang ZN, Yan Y, Liu J, He TT, Thong KT, Ong YK, Chow VTK, Tan K Sen, Wang DY. 2019. Upregulation of cell-surface mucin MUC15 in human nasal epithelial cells upon influenza A virus infection. BMC Infectious Diseases 19:622. DOI: 10.1186/s12879-019-4213-y.

Chen C, Zhang XR, Ju ZY, He WF. 2020. Advances in the research of mechanism and related immunotherapy on the cytokine storm induced by coronavirus disease 2019. Zhonghua shao shang za zhi=Zhonghua shaoshang zazhi $=$ Chinese journal of burns 36:471-475. DOI: 10.3760/cma.j.cn501120-20200224-00088.

Clark NL, Alani E, Aquadro CF. 2012. Evolutionary rate covariation reveals shared functionality and coexpression of genes. Genome Research 22:714-720. DOI: 10.1101/gr.132647.111.

Colgren J, Nichols SA. 2019. Evolution as a guide for experimental cell biology. PLoS Genetics 15:e1007937. DOI: 10.1371/journal.pgen.1007937.

Connors JM, Levy JH. 2020. COVID-19 and its implications for thrombosis and anticoagulation. Blood 135:20332040. DOI: 10.1182/BLOOD.2020006000.

Coperchini F, Chiovato L, Croce L, Magri F, Rotondi M. 2020. The cytokine storm in COVID-19: An overview of the involvement of the chemokine/chemokine-receptor system. Cytokine and Growth Factor Reviews 53:2532. DOI: $10.1016 /$ j.cytogfr.2020.05.003.

Deng Q, Rasool R ur, Russell RM, Natesan R, Asangani IA. 2021. Targeting androgen regulation of TMPRSS2 and ACE2 as a therapeutic strategy to combat COVID-19. iScience 24:102254. DOI: 10.1016/j.isci.2021.102254.

Dolan ME, Hill DP, Mukherjee G, McAndrews MS, Chesler EJ, Blake JA. 2020. Investigation of COVID-19 comorbidities reveals genes and pathways coincident with the SARS-CoV-2 viral disease. Scientific Reports 10:1-11. DOI: 10.1038/s41598-020-77632-8.

Eisenreich A, Orphal M, Böhme K, Kreutz R. 2020. Tmem63c is a potential pro-survival factor in angiotensin IItreated human podocytes. Life Sciences 258. DOI: 10.1016/j.lfs.2020.118175.

Fang Z, Wolf A, Liao Y, McKay A, Fröhlich F, Kimmel J, Xiaohui L, sorrge. 2021. zqfang/GSEApy: gseapyv0.10.3. DOI: 10.5281/ZENODO.4553090.

Fei Y, Tang N, Liu H, Cao W. 2020. Coagulation dysfunction: A hallmark in COVID-19. Archives of Pathology and Laboratory Medicine 144:1223-1229. DOI: 10.5858/arpa.2020-0324-SA.

Fina L, Molgaard H, Robertson D, Bradley N, Monaghan P, Delia D, Sutherland D, Baker M, Greaves M. 1990. Expression of the CD34 gene in vascular endothelial cells. Blood 75:2417-2426. DOI: 10.1182/blood.v75.12.2417.2417.

Findlay GD, Sitnik JL, Wang W, Aquadro CF, Clark NL, Wolfner MF. 2014. Evolutionary Rate Covariation Identifies New Members of a Protein Network Required for Drosophila melanogaster Female Post-Mating Responses. PLoS Genetics 10:e1004108. DOI: 10.1371/journal.pgen.1004108.

Forsbach A, Samulowitz U, Völp K, Hofmann HP, Noll B, Tluk S, Schmitz C, Wader T, Müller C, Podszuweit A,

Peer] reviewing PDF | (2021:06:61975:1:0:NEW 23 Jul 2021) 
964

965

966

967

968

969

970

971

972

973

974

975

976

977

978

979

980

981

982

983

984

985

986

987

988

989

990

991

992

993

994

995

996

997

998

999

1000

1001

1002

1003

1004

1005

1006

1007

1008

1009

1010

1011

1012

Lohner A, Curdt R, Uhlmann E, Vollmer J. 2011. Dual or triple activation of TLR7, TLR8, and/or TLR9 by single-stranded oligoribonucleotides. Nucleic Acid Therapeutics 21:423-436. DOI: 10.1089/nat.2011.0323.

Fricke-Galindo I, Falfán-Valencia R. 2021. Genetics Insight for COVID-19 Susceptibility and Severity: A Review. Frontiers in Immunology 12. DOI: 10.3389/fimmu.2021.622176.

García-Sastre A, Biron CA. 2006. Type 1 interferons and the virus-host relationship: A lesson in détente. Science 312:879-882. DOI: 10.1126/science.1125676.

Garland T, Harvey PH, Ives AR. 1992. Procedures for the analysis of comparative data using phylogenetically independent contrasts. Systematic Biology 41:18-32. DOI: 10.1093/sysbio/41.1.18.

Giurgiu M, Reinhard J, Brauner B, Dunger-Kaltenbach I, Fobo G, Frishman G, Montrone C, Ruepp A. 2019. CORUM: The comprehensive resource of mammalian protein complexes - 2019. Nucleic Acids Research 47:D559-D563. DOI: 10.1093/nar/gky973.

Godin SK, Meslin C, Kabbinavar F, Bratton-Palmer DS, Hornack C, Mihalevic MJ, Yoshida K, Sullivan M, Clark NL, Bernstein KA. 2015. Evolutionary and functional analysis of the invariant SWIM domain in the conserved Shu2/SWS1 protein family from Saccharomyces cerevisiae to Homo sapiens. Genetics 199:10231033. DOI: 10.1534/genetics.114.173518.

Gómez J, Cuesta-Llavona E, Albaiceta GM, García-Clemente M, López-Larrea C, Amado-Rodríguez L, LópezAlonso I, Hermida T, EnrÍquez AI, Gil H, Alonso B, Iglesias S, Suarez-Alvarez B, Alvarez V, Coto E. 2020. The CCR5-delta32 variant might explain part of the association between COVID-19 and the chemokinereceptor gene cluster. medRxiv:2020.11.02.20224659. DOI: 10.1101/2020.11.02.20224659.

Gotluru C, Roach A, Cherry SH, Runowicz CD. 2021. Sex, Hormones, Immune Functions, and Susceptibility to Coronavirus Disease 2019 (COVID-19)-Related Morbidity. Obstetrics and gynecology 137:423-429. DOI: 10.1097/AOG.0000000000004275.

Gupta A, Madhavan M V., Sehgal K, Nair N, Mahajan S, Sehrawat TS, Bikdeli B, Ahluwalia N, Ausiello JC, Wan EY, Freedberg DE, Kirtane AJ, Parikh SA, Maurer MS, Nordvig AS, Accili D, Bathon JM, Mohan S, Bauer KA, Leon MB, Krumholz HM, Uriel N, Mehra MR, Elkind MSV, Stone GW, Schwartz A, Ho DD, Bilezikian JP, Landry DW. 2020. Extrapulmonary manifestations of COVID-19. Nature Medicine 26:1017-1032. DOI: 10.1038/s41591-020-0968-3.

Hanson A, Cohen H, Wang H, Shekhar N, Shah C, Dhaneshwar A, Harvey BW, Murray R, Harvey CJ. 2020. Impaired ICOS signaling between Tfh and B cells distinguishes hospitalized from ambulatory CoViD-19 patients. medRxiv:2020.12.16.20248343. DOI: 10.1101/2020.12.16.20248343.

Hubacek JA, Dusek L, Majek O, Adamek V, Cervinkova T, Dlouha D, Pavel J, Adamkova V. 2021. CCR5 32 Deletion as a Protective Factor in Czech First-Wave COVID-19 Subjects. Physiological Research 70:111115. DOI: $10.33549 /$ physiolres.934647.

Huerta-Cepas J, Serra F, Bork P. 2016. ETE 3: Reconstruction, Analysis, and Visualization of Phylogenomic Data. Molecular Biology and Evolution 33:1635-1638. DOI: 10.1093/molbev/msw046.

Hutloff A, Dittrich AM, Beier KC, Eljaschewitsch B, Kraft R, Anagnostopoulos I, Kroczek RA. 1999. ICOS is an inducible T-cell co-stimulator structurally and functionally related to CD28. Nature 397:263-266. DOI: $10.1038 / 16717$.

Itakura E, Chiba M, Murata T, Matsuura A. 2020. Heparan sulfate is a clearance receptor for aberrant extracellular proteins. Journal of Cell Biology 219. DOI: 10.1083/JCB.201911126.

Jain R, Ramaswamy S, Harilal D, Uddin M, Loney T, Nowotny N, Alsuwaidi H, Varghese R, Deesi Z, Alkhajeh A, Khansaheb H, Alsheikh-Ali A, Abou Tayoun A. 2021. Host transcriptomic profiling of COVID-19 patients with mild, moderate, and severe clinical outcomes. Computational and Structural Biotechnology Journal 19:153-160. DOI: 10.1016/j.csbj.2020.12.016.

Jeffery CJ. 1999. Moonlighting proteins. Trends in Biochemical Sciences 24:8-11. DOI: 10.1016/S09680004(98)01335-8.

Jin HY, Chen LJ, Zhang ZZ, Xu Y Le, Song B, Xu R, Oudit GY, Gao PJ, Zhu DL, Zhong JC. 2015. Deletion of angiotensin-converting enzyme 2 exacerbates renal inflammation and injury in apolipoprotein E-deficient mice through modulation of the nephrin and TNF-alpha-TNFRSF1A signaling. Journal of Translational

Peer] reviewing PDF | (2021:06:61975:1:0:NEW 23 Jul 2021) 
1013

1014

1015

1016

1017

1018

1019

1020

1021

1022

1023

1024

1025

1026

1027

1028

1029

1030

1031

1032

1033

1034

1035

1036

1037

1038

1039

1040

1041

1042

1043

1044

1045

1046

1047

1048

1049

1050

1051

1052

1053

1054

1055

1056

1057

1058

1059

1060

1061

Medicine 13:1-16. DOI: 10.1186/s12967-015-0616-8.

Jones VG, Mills M, Suarez D, Hogan CA, Yeh D, Bradley Segal J, Nguyen EL, Barsh GR, Maskatia S, Mathew R. 2020. COVID-19 and Kawasaki Disease: Novel Virus and Novel Case. Hospital pediatrics 10:537-540. DOI: 10.1542/hpeds.2020-0123.

De Juan D, Pazos F, Valencia A. 2013. Emerging methods in protein co-evolution. Nature Reviews Genetics 14:249-261. DOI: $10.1038 / \mathrm{nrg} 3414$.

Kanehisa M, Goto S. 2000. KEGG: Kyoto Encyclopedia of Genes and Genomes. Nucleic Acids Research 28:27-30. DOI: $10.1093 /$ nar/28.1.27.

Kasela S, Daniloski Z, Jordan TX, Tenoever BR, Sanjana NE, Lappalainen T. 2021. Integrative approach identifies SLC6A20 and CXCR6 as putative causal genes for the COVID-19 GWAS signal in the 3p21.31 locus. medRxiv:2021.04.09.21255184. DOI: 10.1101/2021.04.09.21255184.

Katoh K, Standley DM. 2013. MAFFT multiple sequence alignment software version 7: Improvements in performance and usability. Molecular Biology and Evolution 30:772-780. DOI: 10.1093/molbev/mst010.

Khalili MA, Leisegang K, Majzoub A, Finelli R, Selvam MKP, Henkel R, Mojgan M, Agarwal A. 2020. Male fertility and the COVID-19 pandemic: Systematic review of the literature. World Journal of Men's Health 38:1-15. DOI: 10.5534/WJMH.200134.

Kowalczyk A, Gbadamosi O, Kolor K, Sosa J, Croix CS, Gibson G, Chikina M, Aizenman E, Clark N, Kiselyov K. 2021. Evolutionary rate covariation identifies SLC30A9 (ZnT9) as a mitochondrial zinc transporter. bioRxiv:2021.04.22.440839. DOI: 10.1101/2021.04.22.440839.

Kriventseva E V., Kuznetsov D, Tegenfeldt F, Manni M, Dias R, Simão FA, Zdobnov EM. 2019. OrthoDB v10: Sampling the diversity of animal, plant, fungal, protist, bacterial and viral genomes for evolutionary and functional annotations of orthologs. Nucleic Acids Research 47:D807-D811. DOI: 10.1093/nar/gky1053.

Kriventseva E V., Tegenfeldt F, Petty TJ, Waterhouse RM, Simão FA, Pozdnyakov IA, Ioannidis P, Zdobnov EM. 2015. OrthoDB v8: Update of the hierarchical catalog of orthologs and the underlying free software. Nucleic Acids Research 43:D250-D256. DOI: 10.1093/nar/gku1220.

Kuba K, Imai Y, Ohto-Nakanishi T, Penninger JM. 2010. Trilogy of ACE2: A peptidase in the renin-angiotensin system, a SARS receptor, and a partner for amino acid transporters. Pharmacology and Therapeutics 128:119-128. DOI: 10.1016/j.pharmthera.2010.06.003.

Kumar S, Stecher G, Suleski M, Hedges SB. 2017. TimeTree: A Resource for Timelines, Timetrees, and Divergence Times. Molecular biology and evolution 34:1812-1819. DOI: 10.1093/molbev/msx116.

Lan J, Ge J, Yu J, Shan S, Zhou H, Fan S, Zhang Q, Shi X, Wang Q, Zhang L, Wang X. 2020. Structure of the SARS-CoV-2 spike receptor-binding domain bound to the ACE2 receptor. Nature 581:215-220. DOI: 10.1038/s41586-020-2180-5.

Lazzaroni MG, Piantoni S, Masneri S, Garrafa E, Martini G, Tincani A, Andreoli L, Franceschini F. 2021. Coagulation dysfunction in COVID-19: The interplay between inflammation, viral infection and the coagulation system. Blood Reviews 46:100745. DOI: 10.1016/j.blre.2020.100745.

Lee IH, Lee JW, Kong SW. 2020. A survey of genetic variants in SARS-CoV-2 interacting domains of ACE2, TMPRSS2 and TLR3/7/8 across populations. Infection, Genetics and Evolution 85:104507. DOI: 10.1016/j.meegid.2020.104507.

Leenaerts D, Loyau S, Mertens JC, Boisseau W, Michel JB, Lambeir AM, Jandrot-Perrus M, Hendriks D. 2018. Carboxypeptidase U (CPU, carboxypeptidase B2, activated thrombin-activatable fibrinolysis inhibitor) inhibition stimulates the fibrinolytic rate in different in vitro models. Journal of Thrombosis and Haemostasis 16:2057-2069. DOI: 10.1111/jth.14249.

Lei Y, Takahama Y. 2012. XCL1 and XCR1 in the immune system. Microbes and Infection 14:262-267. DOI: 10.1016/j.micinf.2011.10.003.

Leung LLK, Morser J. 2018. Carboxypeptidase B2 and carboxypeptidase N in the crosstalk between coagulation, thrombosis, inflammation, and innate immunity. Journal of Thrombosis and Haemostasis 16:1474-1486. DOI: $10.1111 /$ jth.14199.

Levi M, Thachil J, Iba T, Levy JH. 2020. Coagulation abnormalities and thrombosis in patients with COVID-19.

Peer] reviewing PDF | (2021:06:61975:1:0:NEW 23 Jul 2021) 
1062

1063

1064

1065

1066

1067

1068

1069

1070

1071

1072

1073

1074

1075

1076

1077

1078

1079

1080

1081

1082

1083

1084

1085

1086

1087

1088

1089

1090

1091

1092

1093

1094

1095

1096

1097

1098

1099

1100

1101

1102

1103

1104

1105

1106

1107

1108

1109

1110

The Lancet Haematology 7:e438-e440. DOI: 10.1016/S2352-3026(20)30145-9.

van Lier D, Kox M, Santos K, van der Hoeven H, Pillay J, Pickkers P. 2021. Increased blood angiotensin converting enzyme 2 activity in critically ill COVID-19 patients. ERJ Open Research 7:00848-02020. DOI: 10.1183/23120541.00848-2020.

Liu D, Yang J, Feng B, Lu W, Zhao C, Li L. 2021. Mendelian randomization analysis identified genes pleiotropically associated with the risk and prognosis of COVID-19. Journal of Infection 82:126-132. DOI: 10.1016/j.jinf.2020.11.031.

López-León S, Wegman-Ostrosky T, Perelman C, Sepulveda R, Rebolledo PA, Cuapio A, Villapol S. 2021. More than 50 Long-Term Effects of COVID-19: A Systematic Review and Meta-Analysis. SSRN Electronic Journal:2021.01.27.21250617. DOI: 10.2139/ssrn.3769978.

Luo P, Liu Y, Qiu L, Liu X, Liu D, Li J. 2020. Tocilizumab treatment in COVID-19: A single center experience. Journal of Medical Virology 92:814-818. DOI: 10.1002/jmv.25801.

Luo S, Zhang X, Xu H. 2020. Don't Overlook Digestive Symptoms in Patients With 2019 Novel Coronavirus Disease (COVID-19). Clinical Gastroenterology and Hepatology 18:1636-1637. DOI: 10.1016/j.cgh.2020.03.043.

Magro C, Mulvey JJ, Berlin D, Nuovo G, Salvatore S, Harp J, Baxter-Stoltzfus A, Laurence J. 2020. Complement associated microvascular injury and thrombosis in the pathogenesis of severe COVID-19 infection: A report of five cases. Translational Research 220:1-13. DOI: 10.1016/j.trsl.2020.04.007.

Mamoor S. 2020. The transcription factor ZBTB43 is differentially expressed and transcriptionally induced in models of coronavirus infection. DOI: 10.31219/osf.io/jhnfv.

Mangalmurti N, Hunter CA. 2020. Cytokine Storms: Understanding COVID-19. Immunity 53:19-25. DOI: 10.1016/j.immuni.2020.06.017.

Matsumoto T, Shiina H, Kawano H, Sato T, Kato S. 2008. Androgen receptor functions in male and female physiology. Journal of Steroid Biochemistry and Molecular Biology 109:236-241. DOI: 10.1016/j.jsbmb.2008.03.023.

McKechnie JL, Blish CA. 2020. The Innate Immune System: Fighting on the Front Lines or Fanning the Flames of COVID-19? Cell Host and Microbe 27:863-869. DOI: 10.1016/j.chom.2020.05.009.

Medcalf RL, Keragala CB, Myles PS. 2020. Fibrinolysis and COVID-19: A plasmin paradox. Journal of Thrombosis and Haemostasis 18:2118-2122. DOI: 10.1111/jth.14960.

Medina-Enríquez MM, Lopez-León S, Carlos-Escalante JA, Aponte-Torres Z, Cuapio A, Wegman-Ostrosky T. 2020. ACE2: the molecular doorway to SARS-CoV-2. Cell and Bioscience 10:1-17. DOI: 10.1186/s13578020-00519-8.

Minh BQ, Schmidt HA, Chernomor O, Schrempf D, Woodhams MD, Von Haeseler A, Lanfear R, Teeling E. 2020. IQ-TREE 2: New Models and Efficient Methods for Phylogenetic Inference in the Genomic Era. Molecular Biology and Evolution 37:1530-1534. DOI: 10.1093/molbev/msaa015.

Misof B, Liu S, Meusemann K, Peters RS, Donath A, Mayer C, Frandsen PB, Ware J, Flouri T, Beutel RG, Niehuis O, Petersen M, Izquierdo-Carrasco F, Wappler T, Rust J, Aberer AJ, Aspöck U, Aspöck H, Bartel D, Blanke A, Berger S, Böhm A, Buckley TR, Calcott B, Chen J, Friedrich F, Fukui M, Fujita M, Greve C, Grobe P, Gu S, Huang Y, Jermiin LS, Kawahara AY, Krogmann L, Kubiak M, Lanfear R, Letsch H, Li Y, Li Z, Li J, Lu H, Machida R, Mashimo Y, Kapli P, McKenna DD, Meng G, Nakagaki Y, Navarrete-Heredia JL, Ott M, Ou Y, Pass G, Podsiadlowski L, Pohl H, Von Reumont BM, Schütte K, Sekiya K, Shimizu S, Slipinski A, Stamatakis A, Song W, Su X, Szucsich NU, Tan M, Tan X, Tang M, Tang J, Timelthaler G, Tomizuka S, Trautwein M, Tong X, Uchifune T, Walzl MG, Wiegmann BM, Wilbrandt J, Wipfler B, Wong TKF, Wu Q, Wu G, Xie Y, Yang S, Yang Q, Yeates DK, Yoshizawa K, Zhang Q, Zhang R, Zhang W, Zhang Y, Zhao J, Zhou C, Zhou L, Ziesmann T, Zou S, Li Y, Xu X, Zhang Y, Yang H, Wang J, Wang J, Kjer KM, Zhou X. 2014. Phylogenomics resolves the timing and pattern of insect evolution. Science 346:763-767. DOI: 10.1126/science. 1257570 .

Morand A, Urbina D, Fabre A. 2020. COVID-19 and Kawasaki like disease : the known-known, the unknownknown and the unknown-unknown. Preprints:2020050160. DOI: 10.20944/PREPRINTS202005.0160.V1.

Peer] reviewing PDF | (2021:06:61975:1:0:NEW 23 Jul 2021) 
1111

1112

1113

1114

1115

1116

1117

1118

1119

1120

1121

1122

1123

1124

1125

1126

1127

1128

1129

1130

1131

1132

1133

1134

1135

1136

1137

1138

1139

1140

1141

1142

1143

1144

1145

1146

1147

1148

1149

1150

1151

1152

1153

1154

1155

1156

1157

1158

1159
Morser J, Shao Z, Nishimura T, Zhou Q, Zhao L, Higgins J, Leung LLK. 2018. Carboxypeptidase B2 and N play different roles in regulation of activated complements $\mathrm{C} 3 \mathrm{a}$ and $\mathrm{C} 5 \mathrm{a}$ in mice. Journal of Thrombosis and Haemostasis 16:991-1002. DOI: 10.1111/jth.13964.

Mosesson MW. 2005. Fibrinogen and fibrin structure and functions. In: Journal of Thrombosis and Haemostasis. John Wiley \& Sons, Ltd, 1894-1904. DOI: 10.1111/j.1538-7836.2005.01365.x.

Myllyharju J, Kivirikko KI. 2001. Collagens and collagen-related diseases. Annals of Medicine 33:7-21. DOI: $10.3109 / 07853890109002055$.

Niazkar HR, Zibaee B, Nasimi A, Bahri N. 2020. The neurological manifestations of COVID-19: a review article. Neurological Sciences 41:1667-1671. DOI: 10.1007/s10072-020-04486-3.

Omarova F, Uitte De Willige S, Ariëns RAS, Rosing J, Bertina RM, Castoldi E. 2013. Inhibition of thrombinmediated factor $\mathrm{V}$ activation contributes to the anticoagulant activity of fibrinogen $\gamma^{\prime}$. Journal of Thrombosis and Haemostasis 11:1669-1678. DOI: 10.1111/jth.12354.

Pagadala NS, Syed K, Tuszynski J. 2017. Software for molecular docking: a review. Biophysical Reviews 9:91-102. DOI: $10.1007 / \mathrm{s} 12551-016-0247-1$.

Pairo-Castineira E, Clohisey S, Klaric L, Bretherick AD, Rawlik K, Pasko D, Walker S, Parkinson N, Fourman MH, Russell CD, Furniss J, Richmond A, Gountouna E, Wrobel N, Harrison D, Wang B, Wu Y, Meynert A, Griffiths F, Oosthuyzen W, Kousathanas A, Moutsianas L, Yang Z, Zhai R, Zheng C, Grimes G, Beale R, Millar J, Shih B, Keating S, Zechner M, Haley C, Porteous DJ, Hayward C, Yang J, Knight J, Summers C, Shankar-Hari M, Klenerman P, Turtle L, Ho A, Moore SC, Hinds C, Horby P, Nichol A, Maslove D, Ling L, McAuley D, Montgomery H, Walsh T, Pereira AC, Renieri A, Shen X, Ponting CP, Fawkes A, Tenesa A, Caulfield M, Scott R, Rowan K, Murphy L, Openshaw PJM, Semple MG, Law A, Vitart V, Wilson JF, Baillie JK. 2021. Genetic mechanisms of critical illness in COVID-19. Nature 591:92-98. DOI: 10.1038/s41586-020$03065-\mathrm{y}$.

Pellegrini M, Marcotte EM, Thompson MJ, Eisenberg D, Yeates TO. 1999. Assigning protein functions by comparative genome analysis: Protein phylogenetic profiles. Proceedings of the National Academy of Sciences of the United States of America 96:4285-4288. DOI: 10.1073/pnas.96.8.4285.

Peng X, Xu E, Liang W, Pei X, Chen D, Zheng D, Zhang Y, Zheng C, Wang P, She S, Zhang Y, Ma J, Mo X, Zhang Y, Ma D, Wang Y. 2016. Identification of FAM3D as a newendogenous chemotaxis agonist for the formyl peptide receptors. Journal of Cell Science 129:1831-1842. DOI: 10.1242/jcs.183053.

Priedigkeit N, Wolfe N, Clark NL. 2015. Evolutionary Signatures amongst Disease Genes Permit Novel Methods for Gene Prioritization and Construction of Informative Gene-Based Networks. PLoS Genetics 11:1-17. DOI: 10.1371/journal.pgen.1004967.

Rabb H. 2020. Kidney diseases in the time of COVID-19: Major challenges to patient care. Journal of Clinical Investigation 130:2749-2751. DOI: 10.1172/JCI138871.

Rao VS, Srinivas K, Sujini GN, Kumar GNS. 2014. Protein-Protein Interaction Detection: Methods and Analysis. International Journal of Proteomics 2014:1-12. DOI: 10.1155/2014/147648.

Raza Q, Choi JY, Li Y, O’Dowd RM, Watkins SC, Chikina M, Hong Y, Clark NL, Kwiatkowski A V. 2019. Evolutionary rate covariation analysis of E-cadherin identifies Raskol as a regulator of cell adhesion and actin dynamics in Drosophila. PLoS Genetics 15:e1007720. DOI: 10.1371/journal.pgen.1007720.

Reilly DF, Westgate EJ, FitzGerald GA. 2007. Peripheral circadian clocks in the vasculature. Arteriosclerosis, Thrombosis, and Vascular Biology 27:1694-1705. DOI: 10.1161/ATVBAHA.107.144923.

Sallard E, Lescure FX, Yazdanpanah Y, Mentre F, Peiffer-Smadja N. 2020. Type 1 interferons as a potential treatment against COVID-19. Antiviral Research 178:104791. DOI: 10.1016/j.antiviral.2020.104791.

Salman AA, Waheed MH, Ali-Abdulsahib AA, Atwan ZW. 2021. Low type i interferon response in covid-19 patients: Interferon response may be a potential treatment for covid-19. Biomedical Reports 14:1-5. DOI: 10.3892/br.2021.1419.

Samavati L, Uhal BD. 2020. ACE2, Much More Than Just a Receptor for SARS-COV-2. Frontiers in Cellular and Infection Microbiology 10:317. DOI: 10.3389/fcimb.2020.00317.

Samuel RM, Majd H, Richter MN, Ghazizadeh Z, Zekavat SM, Navickas A, Ramirez JT, Asgharian H, Simoneau

Peer) reviewing PDF | (2021:06:61975:1:0:NEW 23 Jul 2021) 
1160

1161

1162

1163

1164

1165

1166

1167

1168

1169

1170

1171

1172

1173

1174

1175

1176

1177

1178

1179

1180

1181

1182

1183

1184

1185

1186

1187

1188

1189

1190

1191

1192

1193

1194

1195

1196

1197

1198

1199

1200

1201

1202

1203

1204

1205

1206

1207

1208

CR, Bonser LR, Koh KD, Garcia-Knight M, Tassetto M, Sunshine S, Farahvashi S, Kalantari A, Liu W, Andino R, Zhao H, Natarajan P, Erle DJ, Ott M, Goodarzi H, Fattahi F. 2020. Androgen Signaling Regulates SARS-CoV-2 Receptor Levels and Is Associated with Severe COVID-19 Symptoms in Men. Cell Stem Cell 27:876-889.e12. DOI: 10.1016/j.stem.2020.11.009.

Sánchez-Martín P, Komatsu M. 2020. Heparan sulfate and clusterin: Cleaning squad for extracellular protein degradation. Journal of Cell Biology 219. DOI: 10.1083/JCB.202001159.

Seabold S, Perktold J. 2010. Statsmodels: Econometric and Statistical Modeling with Python. In: Proceedings of the 9th Python in Science Conference. 92-96. DOI: 10.25080/majora-92bf1922-011.

Seitz R, Schramm W. 2020. DIC in COVID-19: Implications for prognosis and treatment? Journal of Thrombosis and Haemostasis 18:1798-1799. DOI: 10.1111/jth.14878.

Severe Covid-19 GWAS Group. 2020. Genomewide Association Study of Severe Covid-19 with Respiratory Failure. New England Journal of Medicine 383:1522-1534. DOI: 10.1056/nejmoa2020283.

Siddiqi HK, Libby P, Ridker PM. 2021. COVID-19 - A vascular disease. Trends in Cardiovascular Medicine 31:15. DOI: 10.1016/j.tcm.2020.10.005.

Singh MK, Mobeen A, Chandra A, Joshi S, Ramachandran S. 2021. A meta-analysis of comorbidities in COVID19: Which diseases increase the susceptibility of SARS-CoV-2 infection? Computers in Biology and Medicine 130:104219. DOI: 10.1016/j.compbiomed.2021.104219.

Sriram K, Insel PA. 2020. A hypothesis for pathobiology and treatment of COVID-19: The centrality of ACE1/ACE2 imbalance. British Journal of Pharmacology 177:4825-4844. DOI: 10.1111/bph.15082.

Stelzer G, Rosen N, Plaschkes I, Zimmerman S, Twik M, Fishilevich S, Iny Stein T, Nudel R, Lieder I, Mazor Y, Kaplan S, Dahary D, Warshawsky D, Guan-Golan Y, Kohn A, Rappaport N, Safran M, Lancet D. 2016. The GeneCards suite: From gene data mining to disease genome sequence analyses. Current Protocols in Bioinformatics 2016:1.30.1-1.30.33. DOI: 10.1002/cpbi.5.

Tafuri A, Shahinian A, Bladt F, Yoshinaga SK, Jordana M, Wakeham A, Boucher LM, Bouchard D, Chan VSF, Duncan G, Odermatt B, Ho A, Itie A, Horan T, Whoriskey JS, Pawson T, Penninger JM, Ohashi PS, Mak TW. 2001. ICOS is essential for effective T-helper-cell responses. Nature 409:105-109. DOI: 10.1038/35051113.

Taquet M, Geddes JR, Husain M, Luciano S, Harrison PJ. 2021. 6-month neurological and psychiatric outcomes in 236379 survivors of COVID-19: a retrospective cohort study using electronic health records. The Lancet Psychiatry 8:416-427. DOI: 10.1016/s2215-0366(21)00084-5.

Terpos E, Ntanasis-Stathopoulos I, Elalamy I, Kastritis E, Sergentanis TN, Politou M, Psaltopoulou T, Gerotziafas G, Dimopoulos MA. 2020. Hematological findings and complications of COVID-19. American Journal of Hematology 95:834-847. DOI: 10.1002/ajh.25829.

Thomas C, Moraga I, Levin D, Krutzik PO, Podoplelova Y, Trejo A, Lee C, Yarden G, Vleck SE, Glenn JS, Nolan GP, Piehler J, Schreiber G, Garcia KC. 2011. Structural linkage between ligand discrimination and receptor activation by Type i interferons. Cell 146:621-632. DOI: 10.1016/j.cell.2011.06.048.

Torra R, Tazón-Vega B, Ars E, Ballarín J. 2004. Collagen type IV ( $\alpha 3-\alpha 4)$ nephropathy: From isolated haematuria to renal failure. Nephrology Dialysis Transplantation 19:2429-2432. DOI: 10.1093/ndt/gfh435.

Uhlén M, Fagerberg L, Hallström BM, Lindskog C, Oksvold P, Mardinoglu A, Sivertsson Å, Kampf C, Sjöstedt E, Asplund A, Olsson IM, Edlund K, Lundberg E, Navani S, Szigyarto CAK, Odeberg J, Djureinovic D, Takanen JO, Hober S, Alm T, Edqvist PH, Berling H, Tegel H, Mulder J, Rockberg J, Nilsson P, Schwenk JM, Hamsten M, Von Feilitzen K, Forsberg M, Persson L, Johansson F, Zwahlen M, Von Heijne G, Nielsen J, Pontén F. 2015. Tissue-based map of the human proteome. Science 347:1260419-1260419. DOI: 10.1126/science.1260419.

Verdecchia P, Cavallini C, Spanevello A, Angeli F. 2020. The pivotal link between ACE2 deficiency and SARSCoV-2 infection. European Journal of Internal Medicine 76:14-20. DOI: 10.1016/j.ejim.2020.04.037.

Virtanen P, Gommers R, Oliphant TE, Haberland M, Reddy T, Cournapeau D, Burovski E, Peterson P, Weckesser W, Bright J, van der Walt SJ, Brett M, Wilson J, Millman KJ, Mayorov N, Nelson ARJ, Jones E, Kern R, Larson E, Carey CJ, Polat İ, Feng Y, Moore EW, VanderPlas J, Laxalde D, Perktold J, Cimrman R, Henriksen I, Quintero EA, Harris CR, Archibald AM, Ribeiro AH, Pedregosa F, van Mulbregt P, Vijaykumar A, Bardelli

Peer] reviewing PDF | (2021:06:61975:1:0:NEW 23 Jul 2021) 
1209

1210

1211

1212

1213

1214

1215

1216

1217

1218

1219

1220

1221

1222

1223

1224

1225

1226

1227

1228

1229

1230

1231

1232

1233

1234

1235

1236

1237

1238

1239

1240

1241

1242

1243

1244

1245

1246

1247

1248

1249

1250

A Pietro, Rothberg A, Hilboll A, Kloeckner A, Scopatz A, Lee A, Rokem A, Woods CN, Fulton C, Masson C, Häggström C, Fitzgerald C, Nicholson DA, Hagen DR, Pasechnik D V., Olivetti E, Martin E, Wieser E, Silva F, Lenders F, Wilhelm F, Young G, Price GA, Ingold GL, Allen GE, Lee GR, Audren H, Probst I, Dietrich JP, Silterra J, Webber JT, Slavič J, Nothman J, Buchner J, Kulick J, Schönberger JL, de Miranda Cardoso JV, Reimer J, Harrington J, Rodríguez JLC, Nunez-Iglesias J, Kuczynski J, Tritz K, Thoma M, Newville M, Kümmerer M, Bolingbroke M, Tartre M, Pak M, Smith NJ, Nowaczyk N, Shebanov N, Pavlyk O, Brodtkorb PA, Lee P, McGibbon RT, Feldbauer R, Lewis S, Tygier S, Sievert S, Vigna S, Peterson S, More S, Pudlik T, Oshima T, Pingel TJ, Robitaille TP, Spura T, Jones TR, Cera T, Leslie T, Zito T, Krauss T, Upadhyay U, Halchenko YO, Vázquez-Baeza Y. 2020. SciPy 1.0: fundamental algorithms for scientific computing in Python. Nature Methods 17:261-272. DOI: 10.1038/s41592-019-0686-2.

Viveiros A, Rasmuson J, Vu J, Mulvagh SL, Yip CYY, Norris CM, Oudit GY. 2021. Sex differences in COVID-19: Candidate pathways, genetics of ACE2, and sex hormones. American Journal of Physiology - Heart and Circulatory Physiology 320:H296-H304. DOI: 10.1152/AJPHEART.00755.2020.

Wiradjaja F, DiTommaso T, Smyth I. 2010. Basement membranes in development and disease. Birth Defects Research Part C - Embryo Today: Reviews 90:8-31. DOI: 10.1002/bdrc.20172.

Wolfe NW, Clark NL. 2015. ERC analysis: Web-based inference of gene function via evolutionary rate covariation. Bioinformatics 31:3835-3837. DOI: 10.1093/bioinformatics/btv454.

Wright FL, Vogler TO, Moore EE, Moore HB, Wohlauer M V., Urban S, Nydam TL, Moore PK, McIntyre RC. 2020. Fibrinolysis Shutdown Correlation with Thromboembolic Events in Severe COVID-19 Infection. Journal of the American College of Surgeons 231:193-203.e1. DOI: 10.1016/j.jamcollsurg.2020.05.007.

Wu S, Miao L, Zhou Q, Gao C, Liu J, Zhan Q, Guo B, Li F, Wang Y, Xu H, Yan H, Wu R, Zhang S, Zheng J, Yang J, Wang S, Yu W, Niu H, Li F, Yang L, Huang J, Lu X, Chen J, Tong Y, Ma L, Zhou Y, Guo Q. 2020. Suppression of Androgen Receptor (AR)-ACE2/TMPRSS2 Axis by AR Antagonists May Be Therapeutically Beneficial for Male COVID-19 Patients. SSRN Electronic Journal. DOI: 10.2139/ssrn.3580526.

Wyatt AR, Wilson MR. 2010. Identification of human plasma proteins as major clients for the extracellular chaperone clusterin. Journal of Biological Chemistry 285:3532-3539. DOI: 10.1074/jbc.M109.079566.

Xie Z, Bailey A, Kuleshov M V., Clarke DJB, Evangelista JE, Jenkins SL, Lachmann A, Wojciechowicz ML, Kropiwnicki E, Jagodnik KM, Jeon M, Ma’ayan A. 2021. Gene Set Knowledge Discovery with Enrichr. Current Protocols 1:e90. DOI: 10.1002/cpz1.90.

Yamada T, Nakao K, Itoh H, Morii N, Shiono S, Sakamoto M, Sugawara A, Saito Y, Mukoyama M, Arai H, Eigyo M, Matsushita A, Imura H. 1988. Inhibitory action of leumorphin on vasopressin secretion in conscious rats. Endocrinology 122:985-990. DOI: 10.1210/endo-122-3-985.

Yan Z, Ye G, Werren JH. 2019. Evolutionary Rate Correlation between Mitochondrial-Encoded and MitochondriaAssociated Nuclear-Encoded Proteins in Insects. Molecular Biology and Evolution 36:1022-1036. DOI: 10.1093/molbev/msz036.

Yeung ML, Teng JLL, Jia L, Zhang C, Huang C, Cai JP, Zhou R, Chan KH, Zhao H, Zhu L, Siu KL, Fung SY, Yung S, Chan TM, To KKW, Chan JFW, Cai Z, Lau SKP, Chen Z, Jin DY, Woo PCY, Yuen KY. 2021. Soluble ACE2-mediated cell entry of SARS-CoV-2 via interaction with proteins related to the reninangiotensin system. Cell 184:2212-2228.e12. DOI: 10.1016/j.cell.2021.02.053.

Van Zundert GCP, Rodrigues JPGLM, Trellet M, Schmitz C, Kastritis PL, Karaca E, Melquiond ASJ, Van Dijk M, De Vries SJ, Bonvin AMJJ. 2016. The HADDOCK2.2 Web Server: User-Friendly Integrative Modeling of Biomolecular Complexes. Journal of Molecular Biology 428:720-725. DOI: 10.1016/j.jmb.2015.09.014.

Peer] reviewing PDF | (2021:06:61975:1:0:NEW 23 Jul 2021) 


\section{Table $\mathbf{1}$ (on next page)}

Top 2\% ERCs for ACE2 and GEN1.

The top two percent (2\%) of ERCs are shown for ACE2 and GEN1, ranked by descending $\rho$ value. The table illustrates how reciprocal ranks can differ between proteins with significant evolutionary correlations, depending on how interconnected proteins are. GEN1 has many partners which rank GEN1 highly in their respective ERCs. Also indicated in the table are examples of reciprocal rank correlations in which both partners rank the other in their top 20 (indicated by bold and asterisks). These are used to construct reciprocal rank protein interaction networks. 


\begin{tabular}{|c|c|c|c|c|c|c|c|c|c|c|c|}
\hline Protein & $\begin{array}{l}\text { ACE2 } \\
\text { Rank }\end{array}$ & $\begin{array}{c}\text { ACE2's } \\
\text { Partner } \\
\text { Rank }\end{array}$ & $\rho$ & $\mathbf{P}$ & FDR & Protein & $\begin{array}{l}\text { GEN1 } \\
\text { Rank }\end{array}$ & $\begin{array}{c}\text { GEN1's } \\
\text { Partner } \\
\text { Rank }\end{array}$ & $\rho$ & $\mathbf{P}$ & FDR \\
\hline GEN1 & 1 & 203 & 0.67 & $4.3 \mathrm{E}-08$ & $4.2 \mathrm{E}-05$ & IFNLR1** & 1 & 1 & 0.89 & $3.2 \mathrm{E}-20$ & $6.2 \mathrm{E}-17$ \\
\hline XCR1 & 2 & 37 & 0.67 & $3.2 \mathrm{E}-08$ & 4.2E-05 & CC2D1B** & 2 & 1 & 0.84 & $5.3 \mathrm{E}-16$ & $5.2 \mathrm{E}-13$ \\
\hline CLU** & 3 & 8 & 0.63 & $3.1 \mathrm{E}-07$ & $1.5 \mathrm{E}-04$ & MUC15** & 3 & 15 & 0.84 & 4.2E-15 & 2.7E-12 \\
\hline TMEM63C** & 4 & 11 & 0.63 & $2.0 \mathrm{E}-07$ & 1.3E-04 & SPZ1 & 4 & 30 & 0.82 & 5.0E-14 & $1.4 \mathrm{E}-11$ \\
\hline IFNAR2 & 5 & 392 & 0.62 & $2.5 \mathrm{E}-06$ & $6.1 \mathrm{E}-04$ & SLC10A6** & 5 & 2 & 0.82 & $1.2 \mathrm{E}-14$ & $5.9 \mathrm{E}-12$ \\
\hline KIF3B & 6 & 26 & 0.60 & 1.7E-06 & 4.9E-04 & ARID4A** & 6 & 9 & 0.81 & 2.0E-14 & $8.0 \mathrm{E}-12$ \\
\hline ITPRIPL2 & 7 & 364 & 0.59 & 1.7E-06 & 4.9E-04 & RAD51AP2 & 7 & 22 & 0.81 & $6.7 \mathrm{E}-14$ & $1.6 \mathrm{E}-11$ \\
\hline FAM227A & 8 & 175 & 0.59 & $1.8 \mathrm{E}-06$ & 4.9E-04 & TESPA1** & 8 & 2 & 0.81 & $3.9 \mathrm{E}-14$ & $1.3 \mathrm{E}-11$ \\
\hline TLR8 & 9 & 243 & 0.58 & 3.7E-06 & 7.2E-04 & IFNAR2** & 9 & 9 & 0.80 & $3.4 \mathrm{E}-12$ & $2.6 \mathrm{E}-10$ \\
\hline COL4A4 & 10 & 541 & 0.58 & $3.7 \mathrm{E}-06$ & 7.2E-04 & BCL6B** & 10 & 1 & 0.80 & $1.6 \mathrm{E}-13$ & $3.6 \mathrm{E}-11$ \\
\hline FAM3D** & 11 & 2 & 0.57 & $5.8 \mathrm{E}-06$ & 8.4E-04 & RTL9 & 11 & 54 & 0.80 & 8.0E-13 & $1.1 \mathrm{E}-10$ \\
\hline F5 & 12 & 642 & 0.57 & 4.1E-06 & 7.2E-04 & COL4A5** & 12 & 8 & 0.80 & $4.9 \mathrm{E}-13$ & 8.7E-11 \\
\hline$A R$ & 13 & 22 & 0.57 & 7.7E-06 & $8.8 \mathrm{E}-04$ & APOBR & 13 & 72 & 0.80 & $1.2 \mathrm{E}-12$ & $1.3 \mathrm{E}-10$ \\
\hline TSGA13 & 14 & 423 & 0.57 & 7.1E-06 & $8.8 \mathrm{E}-04$ & COL4A6** & 14 & 19 & 0.79 & $1.6 \mathrm{E}-12$ & $1.6 \mathrm{E}-10$ \\
\hline PLA2G7 & 15 & 387 & 0.57 & $6.0 \mathrm{E}-06$ & 8.4E-04 & TRADD** & 15 & 6 & 0.79 & $6.8 \mathrm{E}-13$ & $1.0 \mathrm{E}-10$ \\
\hline MMS19 & 16 & 387 & 0.56 & 5.9E-06 & 8.4E-04 & FANCG & 16 & 69 & 0.79 & $4.2 \mathrm{E}-13$ & $8.2 \mathrm{E}-11$ \\
\hline АMOT & 17 & 124 & 0.56 & 8.1E-06 & 8.8E-04 & CD180 & 17 & 27 & 0.78 & 8.4E-13 & $1.1 \mathrm{E}-10$ \\
\hline L1CAM** & 18 & 14 & 0.56 & $8.6 \mathrm{E}-06$ & $8.8 \mathrm{E}-04$ & TNFSF18** & 18 & 7 & 0.78 & $2.6 \mathrm{E}-12$ & $2.2 \mathrm{E}-10$ \\
\hline PDYN & 19 & 428 & 0.56 & 7.3E-06 & $8.8 \mathrm{E}-04$ & АРОВ $* *$ & 19 & 1 & 0.78 & 6.7E-13 & $1.0 \mathrm{E}-10$ \\
\hline IQCD & 20 & 158 & 0.56 & $9.2 \mathrm{E}-06$ & 8.9E-04 & MKKS** & 20 & 20 & 0.78 & 8.7E-13 & $1.1 \mathrm{E}-10$ \\
\hline SERPINA5 & 21 & 468 & 0.56 & $2.2 \mathrm{E}-05$ & $1.4 \mathrm{E}-03$ & PIGV & 21 & 8 & 0.78 & $1.6 \mathrm{E}-12$ & $1.6 \mathrm{E}-10$ \\
\hline CERS4 & 22 & 67 & 0.55 & $2.9 \mathrm{E}-05$ & $1.5 \mathrm{E}-03$ & CCDC17 & 22 & 30 & 0.78 & $1.2 \mathrm{E}-12$ & $1.3 \mathrm{E}-10$ \\
\hline CC2D1B & 23 & 467 & 0.55 & $1.1 \mathrm{E}-05$ & 1.0E-03 & DYTN & 23 & 42 & 0.78 & 8.3E-12 & $5.1 \mathrm{E}-10$ \\
\hline GPR141 & 24 & 17 & 0.55 & $1.5 \mathrm{E}-05$ & $1.2 \mathrm{E}-03$ & GNPTAB & 24 & 36 & 0.77 & 1.7E-12 & $1.6 \mathrm{E}-10$ \\
\hline FSCB & 25 & 817 & 0.55 & $2.8 \mathrm{E}-05$ & $1.5 \mathrm{E}-03$ & MTMR11 & 25 & 13 & 0.77 & $2.9 \mathrm{E}-12$ & $2.3 \mathrm{E}-10$ \\
\hline RGR & 26 & 167 & 0.55 & 3.0E-05 & $1.5 \mathrm{E}-03$ & TNFRSF1A & 26 & 25 & 0.77 & 2.0E-12 & $1.7 \mathrm{E}-10$ \\
\hline COL4A5 & 27 & 529 & 0.55 & 2.1E-05 & $1.4 \mathrm{E}-03$ & IFNAR1 & 27 & 5 & 0.77 & 2.7E-11 & $1.4 \mathrm{E}-09$ \\
\hline TNFSF8 & 28 & 410 & 0.55 & $1.2 \mathrm{E}-05$ & $1.1 \mathrm{E}-03$ & F2RL2 & 28 & 5 & 0.77 & $1.9 \mathrm{E}-11$ & $1.1 \mathrm{E}-09$ \\
\hline CCDC36 & 29 & 576 & 0.55 & $1.5 \mathrm{E}-05$ & $1.2 \mathrm{E}-03$ & CXCR6 & 29 & 1 & 0.77 & 3.1E-11 & $1.5 \mathrm{E}-09$ \\
\hline MRC1 & 30 & 195 & 0.55 & $1.3 \mathrm{E}-05$ & $1.1 \mathrm{E}-03$ & KLHL6 & 30 & 6 & 0.77 & 3.3E-12 & $2.6 \mathrm{E}-10$ \\
\hline CD27 & 31 & 550 & 0.54 & $3.0 \mathrm{E}-05$ & $1.5 \mathrm{E}-03$ & SERPINA5 & 31 & 12 & 0.77 & 2.0E-11 & $1.1 \mathrm{E}-09$ \\
\hline ADCK4 & 32 & 28 & 0.54 & 2.1E-05 & 1.4E-03 & PLA2R1 & 32 & 31 & 0.77 & $6.6 \mathrm{E}-12$ & $4.6 \mathrm{E}-10$ \\
\hline SOWAHA & 33 & 154 & 0.54 & $2.2 \mathrm{E}-05$ & $1.4 \mathrm{E}-03$ & MYCBPAP & 33 & 3 & 0.76 & $4.5 \mathrm{E}-12$ & $3.3 \mathrm{E}-10$ \\
\hline F2RL2 & 34 & 436 & 0.54 & 3.7E-05 & 1.7E-03 & BPIFB2 & 34 & 5 & 0.76 & 7.6E-12 & $4.8 \mathrm{E}-10$ \\
\hline WDR66 & 35 & 302 & 0.54 & 2.1E-05 & 1.4E-03 & TLR7 & 35 & 114 & 0.76 & 1.4E-11 & $8.3 \mathrm{E}-10$ \\
\hline TRADD & 36 & 596 & 0.54 & $2.6 \mathrm{E}-05$ & $1.5 \mathrm{E}-03$ & CCDC190 & 36 & 19 & 0.76 & $2.4 \mathrm{E}-10$ & $6.2 \mathrm{E}-09$ \\
\hline RELA & 37 & 70 & 0.53 & $2.8 \mathrm{E}-05$ & $1.5 \mathrm{E}-03$ & KMT2D & 37 & 95 & 0.76 & 7.1E-12 & $4.8 \mathrm{E}-10$ \\
\hline SLC10A6 & 38 & 533 & 0.53 & 3.0E-05 & $1.5 \mathrm{E}-03$ & FSCB & 38 & 130 & 0.76 & $6.5 \mathrm{E}-11$ & 2.6E-09 \\
\hline IL23A & 39 & 383 & 0.53 & 4.7E-05 & 1.7E-03 & CD27 & 39 & 19 & 0.76 & 2.7E-11 & $1.4 \mathrm{E}-09$ \\
\hline TNFSF18 & 40 & 656 & 0.53 & $5.8 \mathrm{E}-05$ & $1.8 \mathrm{E}-03$ & SNX11 & 40 & 24 & 0.76 & 7.3E-12 & $4.8 \mathrm{E}-10$ \\
\hline
\end{tabular}




\section{Table 2 (on next page)}

Enrichment categories for ACE2's top 2\% proteins by ERC.

Key enrichments include complement and coagulation cascades, cytokine-cytokine signaling, and different pathogen infections. 


\begin{tabular}{|c|c|c|c|c|}
\hline Enrichr Gene set & Term & $\begin{array}{c}\text { FDR } \\
\text { P-value }\end{array}$ & $\begin{array}{l}\text { Odds } \\
\text { Ratio }\end{array}$ & Gene List \\
\hline KEGG_2019_Human & Complement and coagulation cascades & $2.03 \mathrm{E}-03$ & 25.9 & CLU, F2RL2, F5, SERPINA5 \\
\hline KEGG_2019_Human & Cytokine-cytokine receptor interaction & $2.03 \mathrm{E}-03$ & 10.5 & $\begin{array}{l}\text { TNFSF18, IFNAR2, XCR1, IL23A, CD27, } \\
\text { TNFSF8 }\end{array}$ \\
\hline KEGG_2019_Human & Tuberculosis & $1.38 \mathrm{E}-02$ & 11.0 & IL23A, TRADD, MRC1, RELA \\
\hline KEGG_2019_Human & Human papillomavirus infection & $1.38 \mathrm{E}-02$ & 7.6 & IFNAR2, COL4A4, TRADD, COL4A5, RELA \\
\hline KEGG_2019_Human & Protein digestion and absorption & $1.38 \mathrm{E}-02$ & 16.3 & ACE2, COL4A4, COL4A5 \\
\hline KEGG_2019_Human & Pathways in cancer & $1.38 \mathrm{E}-02$ & 5.7 & $\begin{array}{l}\text { IFNAR2, AR, IL23A, COL4A4, COL4A5, } \\
\text { RELA }\end{array}$ \\
\hline KEGG_2019_Human & Small cell lung cancer & $1.38 \mathrm{E}-02$ & 15.8 & COL4A4, COL4A5, RELA \\
\hline KEGG_2019_Human & Amoebiasis & $1.38 \mathrm{E}-02$ & 15.3 & COL4A4, COL4A5, RELA \\
\hline KEGG_2019_Human & $\begin{array}{l}\text { AGE-RAGE signaling pathway in diabetic } \\
\text { complications }\end{array}$ & $1.38 \mathrm{E}-02$ & 14.6 & COL4A4, COL4A5, RELA \\
\hline KEGG_2019_Human & Toll-like receptor signaling pathway & $1.39 \mathrm{E}-02$ & 14.0 & IFNAR2, TLR8, RELA \\
\hline KEGG_2019_Human & Sphingolipid signaling pathway & $1.85 \mathrm{E}-02$ & 12.2 & CERS4, TRADD, RELA \\
\hline KEGG_2019_Human & Relaxin signaling pathway & $2.18 \mathrm{E}-02$ & 11.2 & COL4A4, COL4A5, RELA \\
\hline KEGG_2019_Human & Measles & $2.38 \mathrm{E}-02$ & 10.5 & IFNAR2, TRADD, RELA \\
\hline KEGG_2019_Human & Hepatitis C & $3.05 \mathrm{E}-02$ & 9.3 & IFNAR2, TRADD, RELA \\
\hline KEGG_2019_Human & Cocaine addiction & $3.05 \mathrm{E}-02$ & 19.7 & PDYN, RELA \\
\hline KEGG_2019_Human & PI3K-Akt signaling pathway & 4.17E-02 & 5.5 & IFNAR2, COL4A4, COL4A5, RELA \\
\hline KEGG_2019_Human & $\begin{array}{l}\text { Kaposi sarcoma-associated herpesvirus } \\
\text { infection }\end{array}$ & 4.17E-02 & 7.7 & IFNAR2, TRADD, RELA \\
\hline KEGG_2019_Human & Inflammatory bowel disease (IBD) & 4.34E-02 & 14.7 & IL23A, RELA \\
\hline KEGG_2019_Human & Epstein-Barr virus infection & $4.34 \mathrm{E}-02$ & 7.1 & IFNAR2, TRADD, RELA \\
\hline KEGG_2019_Human & Adipocytokine signaling pathway & 4.34E-02 & 13.8 & TRADD, RELA \\
\hline KEGG_2019_Human & RIG-I-like receptor signaling pathway & 4.34E-02 & 13.6 & TRADD, RELA \\
\hline KEGG_2019_Human & Pertussis & 4.85E-02 & 12.5 & IL23A, RELA \\
\hline GO_Biological_Process_2018 & $\begin{array}{l}\text { tumor necrosis factor-mediated signaling } \\
\text { pathway (GO:0033209) }\end{array}$ & $3.86 \mathrm{E}-03$ & 21.0 & TNFSF18, TRADD, CD27, TNFSF8, RELA \\
\hline GO_Biological_Process_2018 & $\begin{array}{l}\text { cellular response to tumor necrosis } \\
\text { factor (GO:0071356) }\end{array}$ & $1.63 \mathrm{E}-02$ & 13.1 & TNFSF18, TRADD, CD27, TNFSF8, RELA \\
\hline GO_Biological_Process_2018 & $\begin{array}{l}\text { immunoglobulin mediated immune } \\
\text { response (GO:0016064) }\end{array}$ & $1.63 \mathrm{E}-02$ & 154.6 & CD27, TLR8 \\
\hline GO_Biological_Process_2018 & B cell mediated immunity (GO:0019724) & $1.63 \mathrm{E}-02$ & 154.6 & CD27, TLR8 \\
\hline GO_Biological_Process_2018 & $\begin{array}{l}\text { positive regulation of NF-kappaB } \\
\text { transcription factor activity } \\
\text { (GO:0051092) }\end{array}$ & $1.85 \mathrm{E}-02$ & 15.6 & TNFSF18, TRADD, CLU, RELA \\
\hline GO_Biological_Process_2018 & $\begin{array}{l}\text { I-kappaB kinase/NF-kappaB signaling } \\
\text { (GO:0007249) }\end{array}$ & $2.26 \mathrm{E}-02$ & 26.3 & TRADD, TLR8, RELA \\
\hline GO_Biological_Process_2018 & $\begin{array}{l}\text { cytokine-mediated signaling pathway } \\
\text { (GO:0019221) }\end{array}$ & $3.11 \mathrm{E}-02$ & 5.7 & $\begin{array}{l}\text { TNFSF18, IFNAR2, IL23A, TRADD, CD27, } \\
\text { TNFSF8, RELA }\end{array}$ \\
\hline GO_Biological_Process_2018 & $\begin{array}{l}\text { regulation of inflammatory response } \\
\text { (GO:0050727) }\end{array}$ & $3.11 \mathrm{E}-02$ & 11.9 & ACE2, IL23A, PLA2G7, RELA \\
\hline GO_Biological_Process_2018 & $\begin{array}{l}\text { positive regulation of defense response } \\
\text { (GO:0031349) }\end{array}$ & $3.26 \mathrm{E}-02$ & 20.0 & IL23A, TLR8, PLA2G7 \\
\hline WikiPathways_2019_Human & $\begin{array}{l}\text { Complement and Coagulation Cascades } \\
\text { WP558 }\end{array}$ & $2.38 \mathrm{E}-02$ & 25.8 & CLU, F5, SERPINA5 \\
\hline WikiPathways_2019_Human & EBV LMP1 signaling WP262 & 4.24E-02 & 44.2 & TRADD, RELA \\
\hline WikiPathways_2019_Human & $\begin{array}{l}\text { Toll-like Receptor Signaling Pathway } \\
\text { WP75 }\end{array}$ & $4.24 \mathrm{E}-02$ & 14.2 & IFNAR2, TLR8, RELA \\
\hline WikiPathways_2019_Human & Toll-like Receptor Signaling WP3858 & 4.36E-02 & 32.0 & TLR8, RELA \\
\hline WikiPathways_2019_Human & $\begin{array}{l}\text { miRNAs involvement in the immune } \\
\text { response in sepsis WP4329 }\end{array}$ & $4.95 \mathrm{E}-02$ & 26.5 & TLR8, RELA \\
\hline WikiPathways_2019_Human & $\begin{array}{l}\text { Regulation of toll-like receptor signaling } \\
\text { pathway WP1449 }\end{array}$ & 4.96E-02 & 10.4 & IFNAR2, TLR8, RELA \\
\hline
\end{tabular}


Table 3(on next page)

ACE2-derived coagulation and blood-related proteins.

Coagulation and blood-related proteins in the ACE2 CRR and URR Networks as well as the top 1\% ACE2 ERC list. 


\begin{tabular}{|c|c|c|}
\hline Name & Full Name & Brief Description \\
\hline ACE2 & Angiotensin-Converting Enzyme 2 & $\begin{array}{l}\text { Catalyzes the cleavage of angiotensin I to angiotensin 1-9 and } \\
\text { angiotensin II to angiotensin 1-7 (Burrell et al., 2004) }\end{array}$ \\
\hline FGA & Fibrinogen alpha chain & $\begin{array}{l}\text { Bind to FGB and FGG to form fibrinogen, used to form blood clots } \\
\text { (Mosesson, 2005) }\end{array}$ \\
\hline FGB & Fibrinogen beta chain & $\begin{array}{l}\text { Bind to FGA and FGG to form fibrinogen, used to form blood clots } \\
\text { (Mosesson, 2005) }\end{array}$ \\
\hline FGG & Fibrinogen gamma chain & $\begin{array}{l}\text { Bind to FGA and FGB to form fibrinogen, used to form blood clots } \\
\text { (Mosesson, 2005) }\end{array}$ \\
\hline CPB2 & Carboxypeptidase B2 & Inhibits fibrinolysis (Leenaerts et al., 2018) \\
\hline SERPINF2 & $\begin{array}{l}\text { Serpin family F member } 2 \\
\text { (alpha-2-antiplasmin) }\end{array}$ & $\begin{array}{l}\text { Inhibits Plasmin, a protein involved in fibrinolysis (Kanehisa \& Goto, } \\
\text { 2000) }\end{array}$ \\
\hline CD34 & CD34 molecule & Associated with hematopoiesis and stem cells (Fina et al., 1990) \\
\hline CLU & Clusterin & Binds to Fibrinogen (Wyatt \& Wilson, 2010) \\
\hline MAS1 & $\begin{array}{l}\text { MAS1 Proto-Oncogene, } \\
\text { G Protein-Coupled Receptor }\end{array}$ & Receptor for angiotensin-(1-7) (Burrell et al., 2004) \\
\hline FAM3D & $\begin{array}{l}\text { FAM3 Metabolism Regulating } \\
\text { Signaling Molecule D }\end{array}$ & $\begin{array}{l}\text { Implicated in inflammatory responses in the gastrointestinal tract and is } \\
\text { a chemoattractant for neutrophiles and monocytes (Peng et al., 2016) }\end{array}$ \\
\hline GPR141 & G Protein-Coupled Receptor 141 & $\begin{array}{l}\text { High expression in blood, granulocytes, Kupfer cells, and macrophages } \\
\text { (Stelzer et al., 2016) }\end{array}$ \\
\hline TMEM63C & Transmembrane Protein 63C & Interacts with angiotensin II (Eisenreich et al., 2020) \\
\hline LECT2 & $\begin{array}{l}\text { Leukocyte Cell-derived } \\
\text { Chemotaxin } 2\end{array}$ & $\begin{array}{l}\text { Involved in macrophage activation, insulin resistance and diabetes, and } \\
\text { neutrophil chemotaxis (Yamagoe et al., 1996; Zhang et al., 2018; Takata } \\
\text { et al., 2021) }\end{array}$ \\
\hline ETS1 & $\begin{array}{l}\text { ETS proto-oncogene } 1 \text {, } \\
\text { transcription factor }\end{array}$ & $\begin{array}{l}\text { Transcription factor involved in cytokine/chemokine processes and } \\
\text { angiogenesis (Stelzer et al., 2016) }\end{array}$ \\
\hline ZВТВ43 & $\begin{array}{l}\text { Zinc Finger and BTB Domain } \\
\text { containing } 43\end{array}$ & $\begin{array}{l}\text { Associated with Diamond-Blackfan Anemia 4, in which the bone } \\
\text { marrow is unable to make enough red blood cells to carry oxygen } \\
\text { (Stelzer et al., 2016) }\end{array}$ \\
\hline COL4A4 & Collagen Type IV Alpha 4 & $\begin{array}{l}\text { Subunit of Collagen Type 4, which are a part of the basement } \\
\text { membrane which resides between epithelial cells (Stelzer et al., 2016) }\end{array}$ \\
\hline F13B & Coagulation Factor XIII B chain & $\begin{array}{l}\text { Stabilizes F13A subunits, while it does not have enzymatic abilities it is } \\
\text { thought to be a plasma carrier molecule (Stelzer et al., 2016) }\end{array}$ \\
\hline AMOT & Angiomotin & $\begin{array}{l}\text { Associated with angiogenesis and endothelial cell movement (Bratt et } \\
\text { al., 2005; Aase et al., 2007) }\end{array}$ \\
\hline PDYN & Prodynorphin & Inhibits vasopressin secretion (Yamada et al., 1988) \\
\hline
\end{tabular}




\section{Figure 1}

Evolutionary rate correlations.

The Spearman rank correlations between two proteins are calculated based on rates of protein evolution on terminal branches of a phylogeny. The relative rates of two proteins (red and blue lines) are shown in the hypothetical phylogenetic trees. Correlated and uncorrelated protein rates are illustrated below using a larger number of terminal branches (data points) than presented in the phylogeny. 


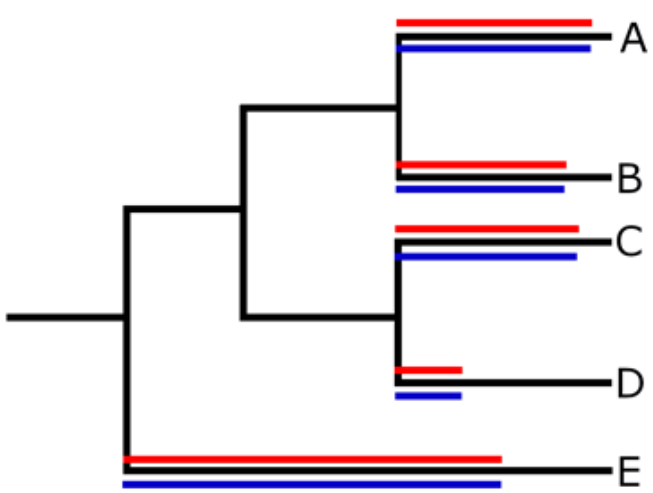

Strong Positive Correlation

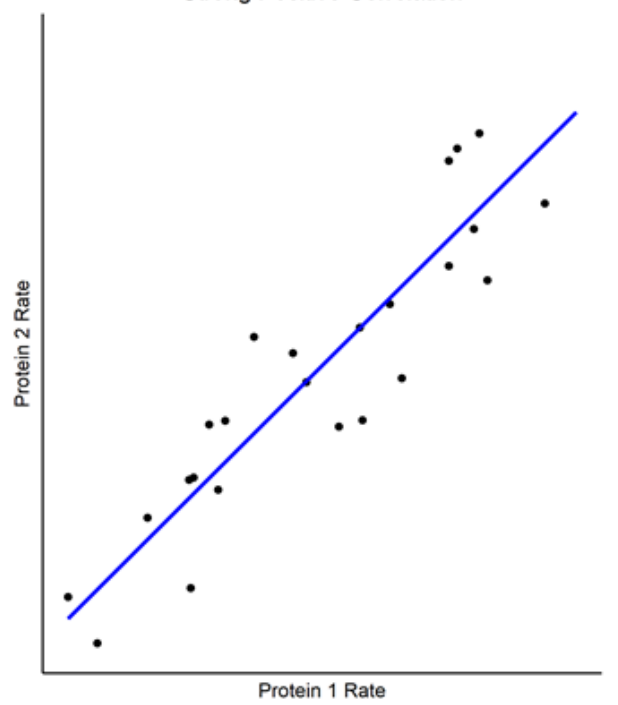

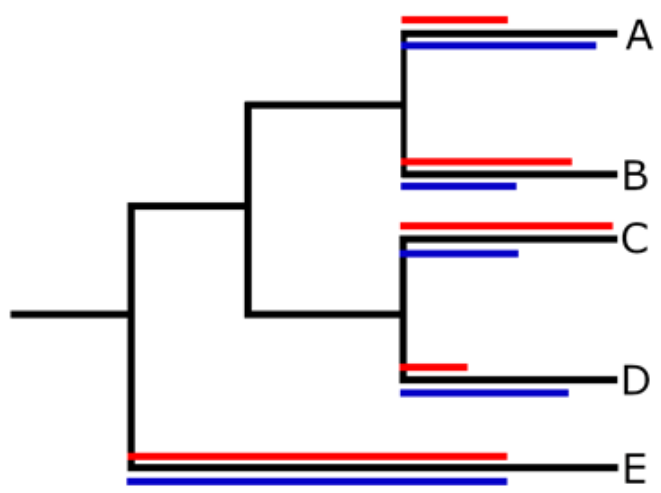

No Correlation

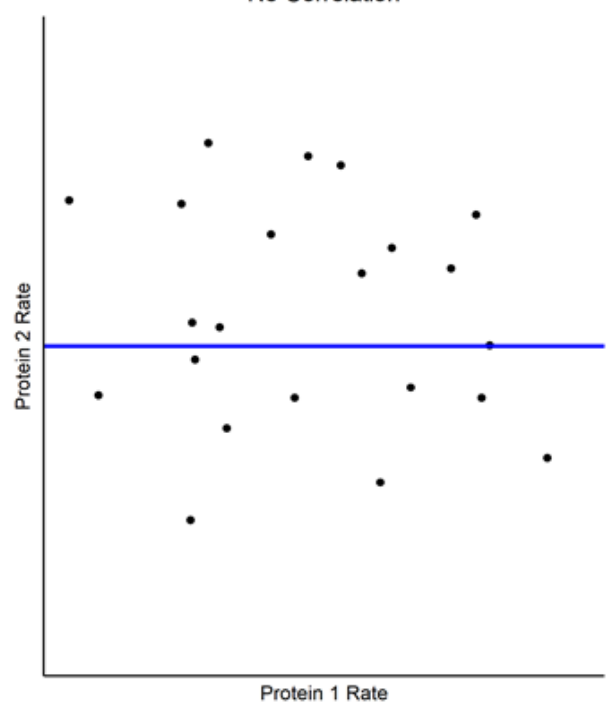




\section{Figure 2}

Modified KEGG coagulation pathway.

The KEGG Coagulation pathway (Kanehisa \& Goto, 2000), with ACE2-CLU-GPR141 associated proteins (based on presence on any of their top $2 \%$ ERCs or in the ACE2 CRR network) indicated in red. The KEGG pathway has been supplemented to indicate the three fibrinogen proteins and clusterin associations previously discussed. Note the alternate protein names: PAR3,4 = F2RL2 \& F2RL3 = Thrombin receptors; $\alpha 2 A P=$ SERPINF2 = Alpha-2-antiplasmin; $\mathrm{tPA}=\mathrm{PLAT} ;$ and $\mathrm{PCI}=\mathrm{SERPINA} 5=$ Protein $\mathrm{C}$ Inhibitor . 


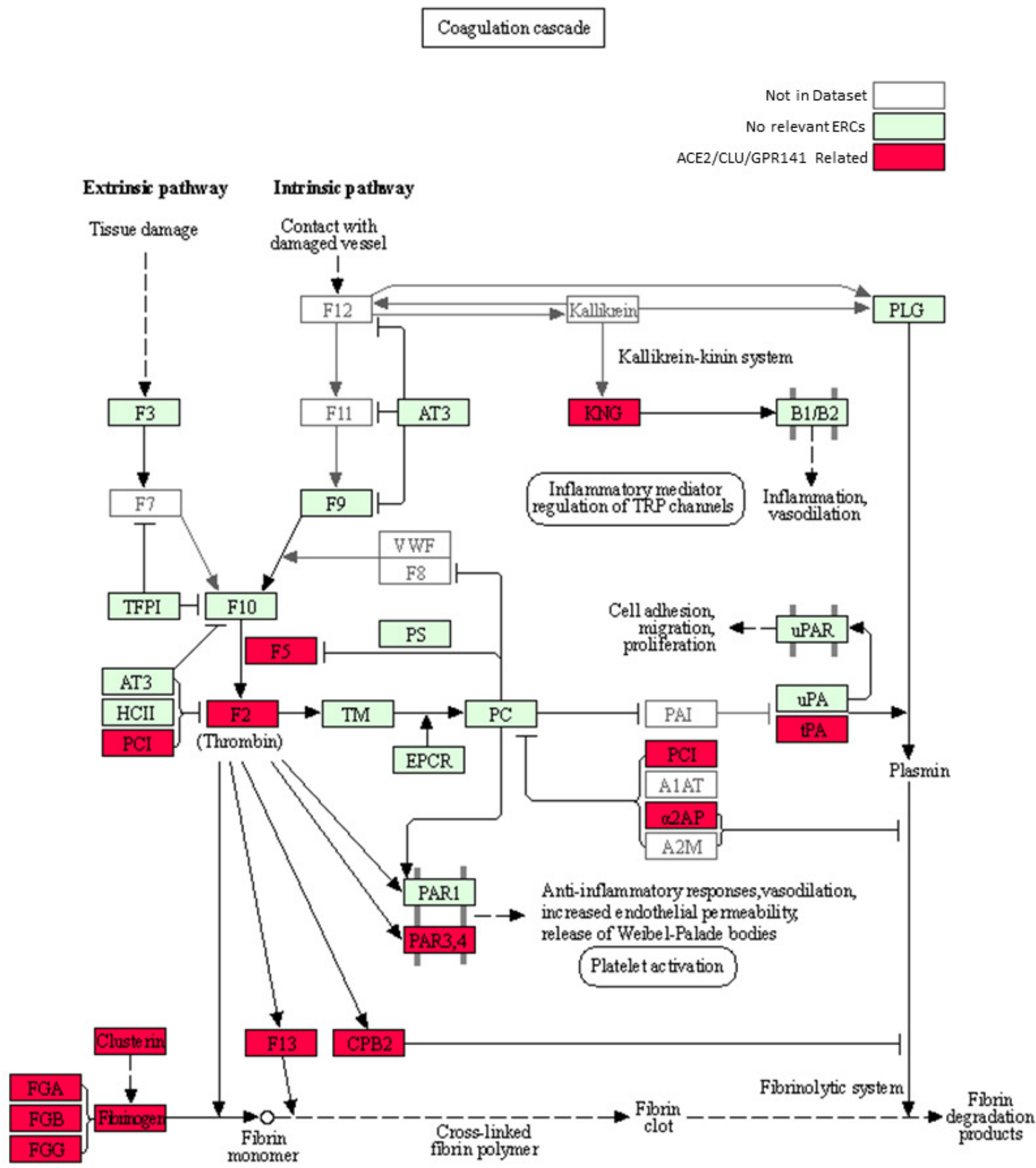

04610 10/29/19

(c) Kanehisa Laboratories 


\section{Figure 3}

ACE2 centric reciprocal rank (CRR) network.

Proteins with ERC reciprocal ranks $\leq 20$ are shown by double-headed arrows, and unidirectional ranks $\leq 20$ connecting to the RR backbone are indicated by single-headed arrows. ACE2 has extensive connections to coagulation proteins mediated primarily through Clusterin (CLU) and GPR141. ACE2 is highlighted in purple, and blue shading intensity indicates the level of reciprocal connectivity for different proteins.

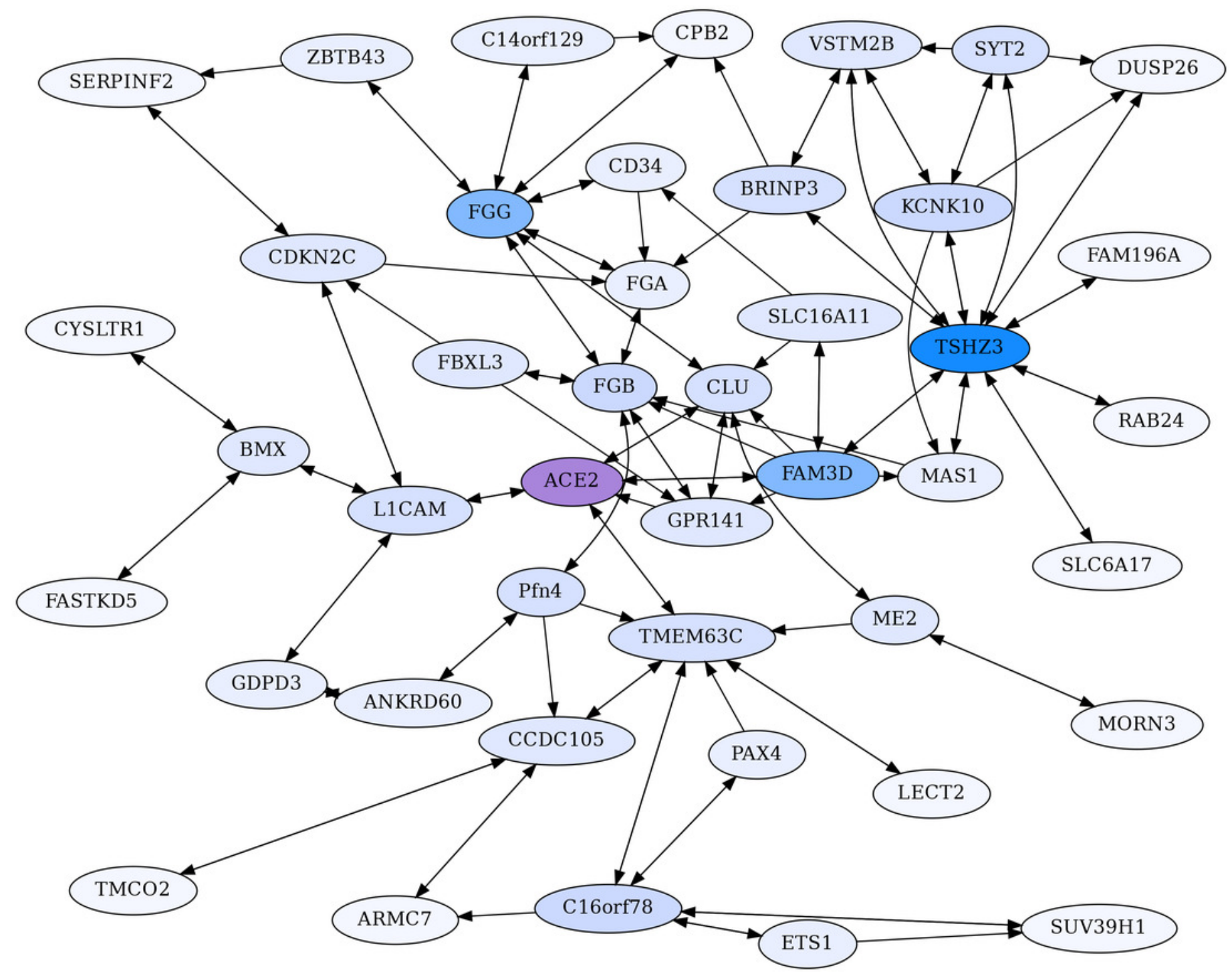




\section{Figure 4}

ACE2 unidirectional reciprocal rank (URR) network.

ACE2's top 10 unidirectional ERC proteins for a web of reciprocal rank (RR20) connections.

The network is particularly enriched for cytokine signaling and immunity. Highly interconnected proteins include COL4A5, F5, GEN1, and IFNAR2. ACE2 is highlighted in purple, and blue shading intensity indicates the level of reciprocal connectivity for different proteins.

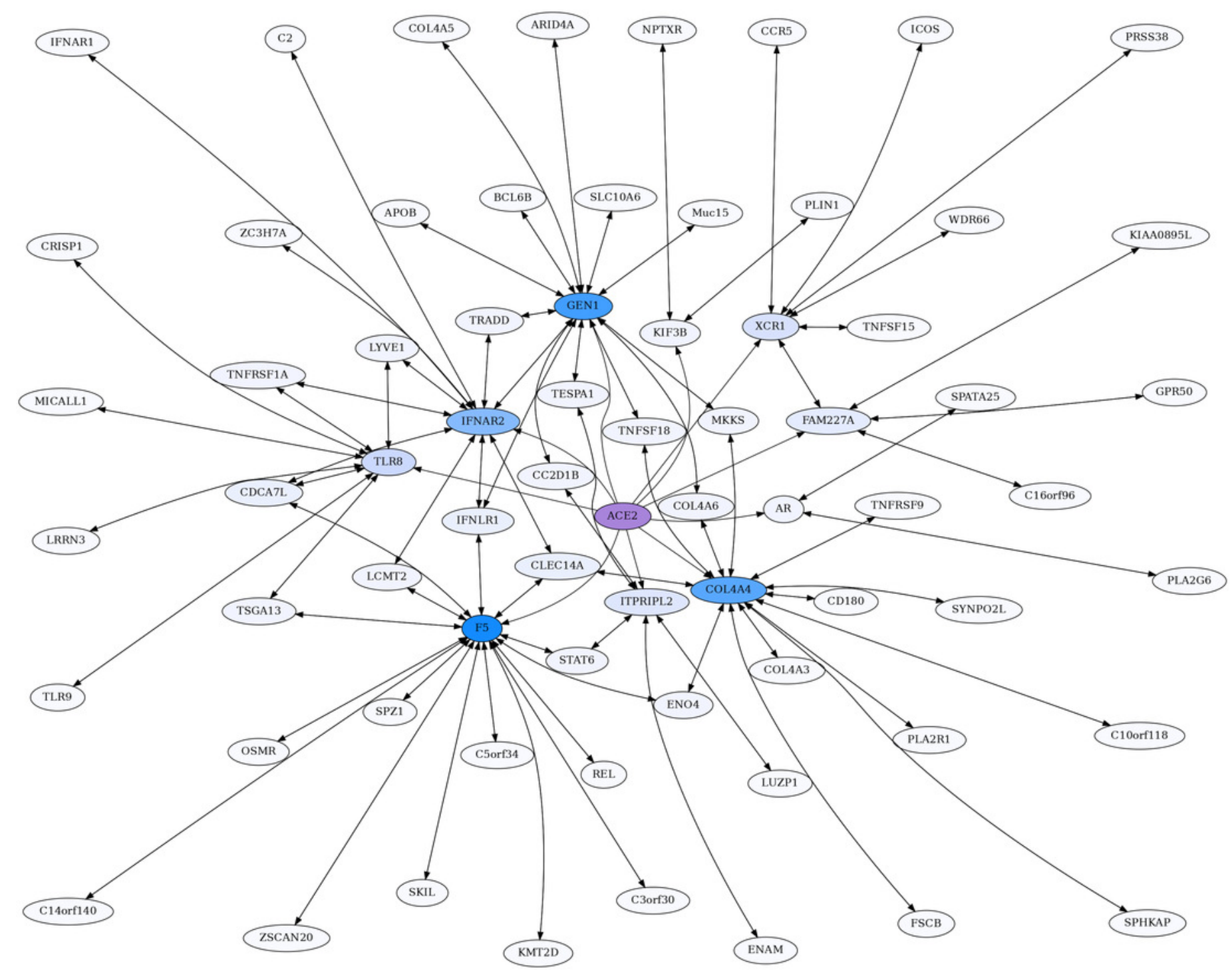


Figure 5

COL4A4-centric RR20 network.

This network detects reciprocal rank 20 ERCs of different proteins to COL4A4, including other Type IV Collagen proteins known to form complexes with COL4A4.

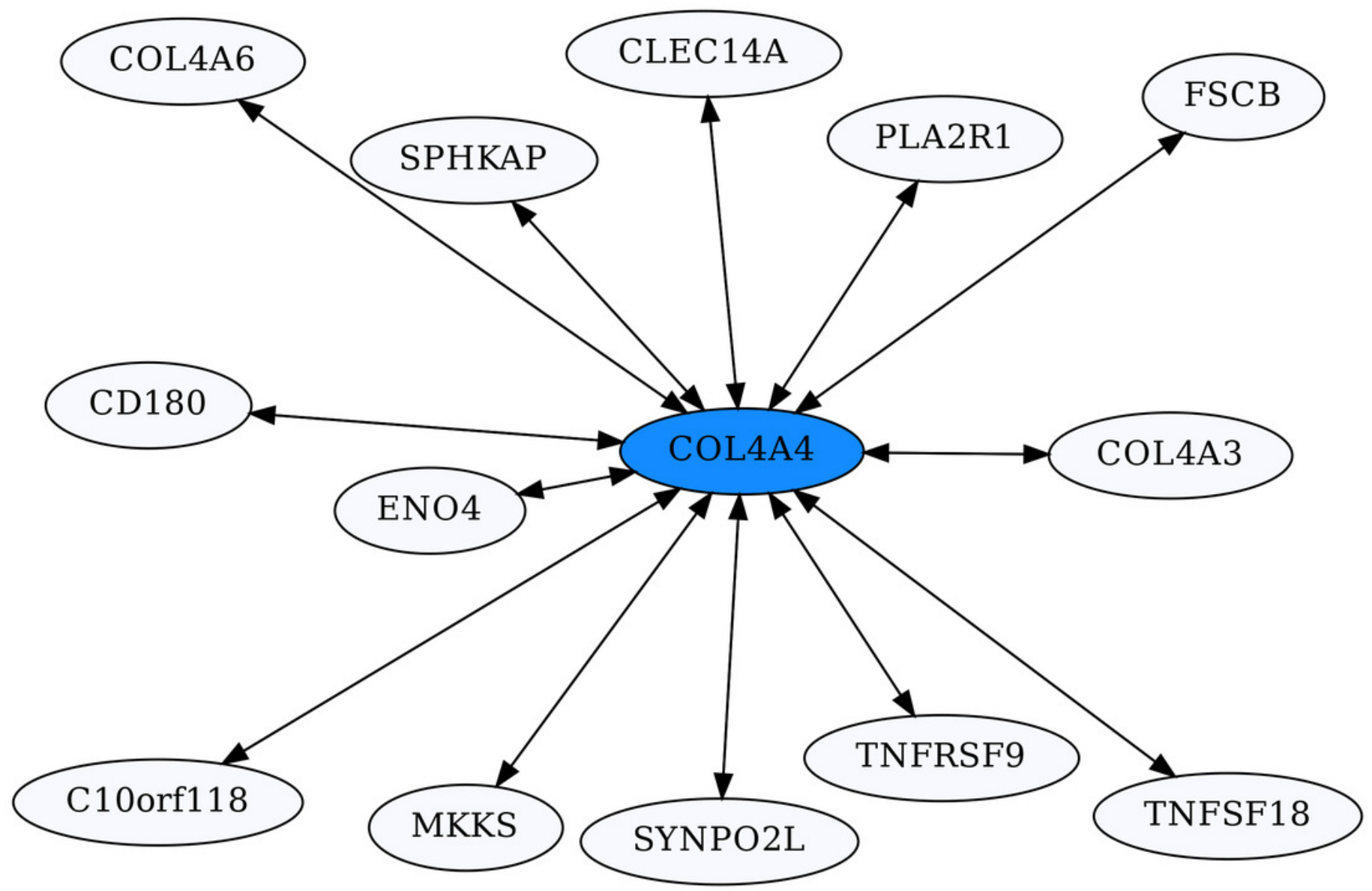


Figure 6

Coagulation Factor V-centric RR20 network.

The network captures strong reciprocal ERCs between F5 and proteins related to immune function such as IFNLR1.

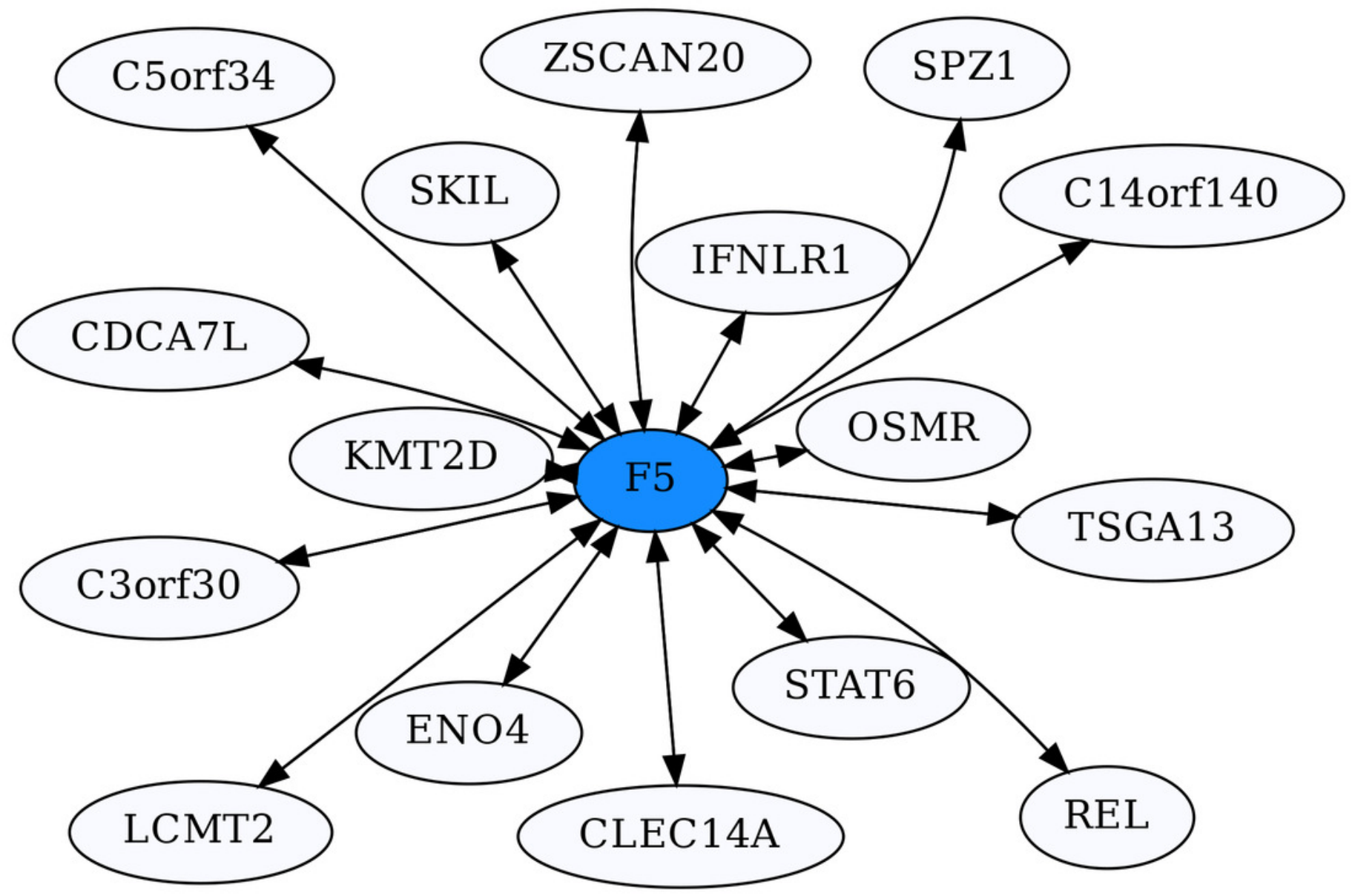

